\title{
Atrial natriuretic factor receptor guanylate cyclase, ANF-RGC, transduces two independent signals, ANF and $\mathrm{Ca}^{2+}$
}

\section{Teresa Duda*, Alexandre Pertzev and Rameshwar K. Sharma}

The Unit of Regulatory and Molecular Biology, Research Divisions of Biochemistry and Molecular Biology, Salus University, Elkins Park, PA, USA

\section{Edited by:}

Clint L. Makino, Massachusetts Eye and Ear Infirmary and Harvard

Medical School, USA

\section{Reviewed by:}

Peter Jedlicka, Goethe University, Germany

Baojin Ding, University of

Massachusetts Medical School, USA

${ }^{*}$ Correspondence:

Teresa Duda, The Unit of Regulatory and Molecular Biology, Research

Divisions of Biochemistry and

Molecular Biology, Salus University, 8360 Old York Road, Elkins Park, PA 19027, USA

e-mail: tduda@salus.edu
Atrial natriuretic factor receptor guanylate cyclase (ANF-RGC), was the first discovered member of the mammalian membrane guanylate cyclase family. The hallmark feature of the family is that a single protein contains both the site for recognition of the regulatory signal and the ability to transduce it into the production of the second messenger, cyclic GMP. For over two decades, the family has been classified into two subfamilies, the hormone receptor subfamily with ANF-RGC being its paramount member, and the $\mathrm{Ca}^{2+}$ modulated subfamily, which includes the rod outer segment guanylate cyclases, ROS-GC1 and 2, and the olfactory neuroepithelial guanylate cyclase. ANF-RGC is the receptor and the signal transducer of the most hypotensive hormones, ANF- and B-type natriuretic peptide (BNP). After binding these hormones at the extracellular domain it, at its intracellular domain, signals activation of the C-terminal catalytic module and accelerates the production of cyclic GMP. Cyclic GMP then serves the second messenger role in biological responses of ANF and BNP such as natriuresis, diuresis, vasorelaxation, and anti-proliferation. Very recently another modus operandus for ANF-RGC was revealed. Its crux is that ANF-RGC activity is also regulated by $\mathrm{Ca}^{2+}$. The $\mathrm{Ca}^{2+}$ sensor neurocalcin $\mathrm{d}$ mediates this signaling mechanism. Strikingly, the $\mathrm{Ca}^{2+}$ and ANF signaling mechanisms employ separate structural motifs of ANF-RGC in modulating its core catalytic domain in accelerating the production of cyclic GMP. In this review the biochemistry and physiology of these mechanisms with emphasis on cardiovascular regulation will be discussed.

Keywords: atrial natriuretic factor, atrial natriuretic factor receptor guanylate cyclase, calcium, cyclic GMP, neurocalcin $\delta$, signal transduction

\section{INTRODUCTION}

In the 1980s, the field of cellular signal transduction underwent total metamorphosis. Until then only two major paradigms of signal transduction, that of cyclic AMP and that of $\mathrm{IP}_{3}$ (inositol triphosphate) were known and were used to explain cellular signaling mechanisms and the second messenger concepts. Each of these two paradigms constituted an assemblage of three components - receptor, GTP binding protein, and the transducer catalyst - necessary for signal transduction. The astonishing discovery of a novel membrane protein that was simultaneously a receptor of a hormone and the transducer of its signal

Abbreviations: ANF, atrial natriuretic factor; ANF-RGC, atrial natriuretic factor receptor guanylate cyclase; ARM, ATP-regulatory module; ATP, adenosine triphosphate; BNP, B-type natriuretic peptide; CNP, C-type natriuretic peptide; CNP-RGC, C-type natriuretic peptide receptor guanylate cyclase; cyclic AMP, $3^{\prime}, 5^{\prime}$-cyclic adenosine monophosphate; cyclic GMP, 3', $5^{\prime}$-cyclic guanosine monophosphate; CNG channel, cyclic nucleotide gated channel; GCAP, guanylate cyclase activating protein; GC-A, guanylate cyclase-A; GC-B, guanylate cyclase-B; GC-C, guanylate cyclase- $\mathrm{C}$ GC-D, guanylate cyclase-D; GC-E, guanylate cyclase-E; GC-F, guanylate cyclaseF; GC-G, guanylate cyclase-G; KHD, kinase homology domain; K-LD, kinase-like domain; NC $\delta$, neurocalcin $\delta$; NPR-A, natriuretic peptide receptor-A; ONE-GC, olfactory neuroepithelial guanylate cyclase; STa-RGC, heat-stable enterotoxin (also guanylin and uroguanylin) receptor guanylate cyclase; ROS-GC, rod outer segment guanylate cyclase. added a new dimension to our understanding of cellular signal transduction. The hormone was the newly described atrial natriuretic factor (ANF; de Bold, 1985) and the membrane protein was both its receptor and guanylate cyclase enzyme, termed therefore atrial natriuretic factor receptor guanylate cyclase (ANFRGC; Kuno et al., 1986; Paul, 1986; Paul et al., 1987; Takayanagi et al., 1987; Meloche et al., 1988). Other terms to describe the protein are GC-A and NPR-A. ANF-RGC responded to ANF binding with accelerated synthesis of its second messenger cyclic GMP. The novelty of the system was 2-fold; first, a single protein, ANF-RGC, which contained both the ability to recognize the ANF hormonal signal and the activity to translate the hormonal information into the production of its second messenger, cyclic GMP was identified; and second, cyclic GMP was recognized as bona fide hormonal second messenger. Until then, the majority of laboratories forcefully denied the hormonal second messenger role of cyclic GMP (reviewed in Sharma, 2002, 2010).

The concept that ANF-RGC is indeed both hormone receptor and a catalyst was further supported by cloning studies (Chinkers et al., 1989; Lowe etal., 1989; Pandey and Singh, 1990; Duda et al., 1991; Marala et al., 1992). Homology cloning made possible finding other receptor membrane guanylate cyclases: C-type 
natriuretic peptide receptor guanylate cyclase, CNP-RGC (also known as GC-B; Chang etal., 1989; Schulz et al., 1989; Duda et al., 1993b) and heat-stable enterotoxin (also guanylin and uroguanylin) receptor guanylate cyclase, STa-RGC (GC-C; Schulz etal., 1990; de Sauvage etal., 1991; Singh etal., 1991; Hamra et al., 1993; Khare et al., 1994). Identification of these three structurally and functionally related membrane guanylate cyclases that were receptors for hormonally active peptides resulted in a notion that all membrane guanylate cyclases, even those still to be discovered, were receptors for specific extracellular ligands.

The notion was short-lived, however. The next four, in chronological order, identified membrane guanylate cyclases: the rod outer segment guanylate cyclases, ROS-GC1 (also known as RetGC1 or GC-E; Koch, 1991; Shyjan et al., 1992; Goraczniak et al., 1994) and ROS-GC2 (RetGC2 or GC-F; Lowe et al., 1995; Yang et al., 1995; Goraczniak et al., 1998), the olfactory neuroepithelium guanylate cyclase, ONE-GC (also termed as GC-D) (Fulle et al., 1995; Duda et al., 2001a) and GC-G (Schulz et al., 1998), did not respond with increased activity to any extracellular ligand. They were therefore branded as "orphan receptors" (Fulle et al., 1995; Yang etal., 1995; Wedel and Garbers, 1997; Schulz et al., 1998).

ROS-GC1 and ROS-GC2 were not orphan RGC, however. Biochemical and physiological findings began to reveal that regulation of their catalytic activities is specific to their physiological function which is to return the illuminated photoreceptors to the dark, resting state. The illumination leads to activation of cyclic GMP phosphodiesterase, depletion of cyclic GMP, closure of the cyclic GMP gated (CNG) channels, and lowering the free $\mathrm{Ca}^{2+}$ concentration (reviewed in Pugh et al., 1997; Koch et al., 2010). The ROS-GCs' task is to restore the dark-level of cyclic GMP allowing opening of the $\mathrm{CNG}$ channels and increase of $\mathrm{Ca}^{2+}$ influx. $\mathrm{Ca}^{2+}$ concentration, thus, determines the activity of ROS-GCs but it occurs in an indirect way. Guanylate cyclase activating proteins (GCAPs) sense the post-illumination fall in $\mathrm{Ca}^{2+}$ and stimulate ROS-GCs to resynthesize cyclic GMP at a faster rate (reviewed in Detwiler, 2000; Koch et al., 2010). In this cyclic GMP-Ca ${ }^{2+}$ feedback mechanism, ROS-GCs do not respond to an extracellular ligand but to their intracellular $\mathrm{Ca}^{2+}$ sensing ligands, the GCAPs (Palczewski etal., 1994; Dizhoor et al., 1995; Duda et al., 1996b).

Soon thereafter the evidence began to emerge, primarily from our laboratory, that GCAPs are not the only $\mathrm{Ca}^{2+}$ sensing modulators of ROS-GC activity. While increasing $\mathrm{Ca}^{2+}$ concentrations inhibit ROS-GCs activity through GCAPs, two other $\mathrm{Ca}^{2+}$ sensors, S100B, and neurocalcin $\delta(\mathrm{NC} \delta)$ stimulate ROS-GC1 in a $\mathrm{Ca}^{2+}$. dependent fashion (Pozdnyakov et al., 1995; Duda et al., 1996a; Margulis et al., 1996; Kumar et al., 1999). The $\mathrm{Ca}^{2+}$-dependent S100B-mediated activation of ROS-GC operates in cones including their outer segments and pedicles (Wen et al., 2012). Its role in photo- and visual transductions remains to be established, but existing data indicate its involvement in transmission of the visual signal from cone ON-bipolar cells (Wen et al., 2012). $\mathrm{Ca}^{2+}$ signaling of ROS-GC activity mediated by NC $\delta$ is operative in retinal ganglion cells (Krishnan et al., 2004) but its linkage with the visual transduction is not clear yet.
Similar, but with additional twists, regulation of ONE-GC occurs in a subset of olfactory sensory neurons (Fulle et al., 1995; Duda et al., 2001a; Pertzev et al., 2010). The cyclase was initially classified as a member of the $\mathrm{Ca}^{2+}$ modulated subfamily (Duda et al., 2001a). Its activity is modulated in a $\mathrm{Ca}^{2+}$-dependent fashion by NC $\delta$ (Duda et al., 2001a, 2004) and by GCAP1 (Duda et al., 2006, 2012a; Pertzev et al., 2010). Remarkably, the Ca ${ }^{2+}$-GCAP1 pattern of ONE-GC modulation is opposite to that of ROS-GC modulation. Sensing increasing concentrations of $\mathrm{Ca}^{2+}$ GCAP1 stimulates ONE-GC while it inhibits ROS-GC (Duda et al., 2006, 2012a).

After the $\mathrm{Ca}^{2+}$-dependent modulation of ONE-GC activity was demonstrated, an extracellular ligand of the cyclase was found. The ligand was the odorant uroguanylin (Leinders-Zufall et al., 2007; Duda and Sharma, 2008; reviewed in Sharma and Duda, 2010; Zufall and Munger, 2010). Hence, ONE-GC responds to both extracellular (uroguanylin) and intracellular $\mathrm{Ca}^{2+}$ signals. At this point a new, two-step "cross-talk" odorant transduction model was proposed (Duda and Sharma, 2009). In "step 1," the odorant uroguanylin interacts with the receptor domain of ONEGC, causing its minimal activation. The cyclic GMP generated in response to uroguanylin signal opens a few of the CNG3 channels leading to some increase in $\left[\mathrm{Ca}^{2+}\right]_{\mathrm{i}}$ in the odorant receptor cell. In "step 2," the membrane bound NC $\delta$ and GCAP1 sense the increase in $\left[\mathrm{Ca}^{2+}\right]_{\mathrm{i}}$ and in their $\mathrm{Ca}^{2+}$-bound states fully activate ONEGC triggering maximal influx of $\mathrm{Ca}^{2+}$ and depolarization of the olfactory receptor cell membrane.

The odorant receptor ONE-GC linkage with the intracellular free $\mathrm{Ca}^{2+}$ signals brought forth a question whether this cyclase is a unique case of dually regulated membrane guanylate cyclase. Latest studies from our laboratory demonstrate that it is not. The nascent member of the hormone receptor subfamily, the ANF$\mathrm{RGC}$, is also responsive to $\mathrm{Ca}^{2+}$ (Duda et al., 2012a,b) and NC $\delta$ is the sensor protein which communicates the $\mathrm{Ca}^{2+}$ signal to ANFRGC and in the $\mathrm{Ca}^{2+}$-bound state, activates ANF-RGC activity. The two modes of ANF-RGC activation, hormonal and $\mathrm{Ca}^{2+}$ dependent, engage their specific and independent pathways of transmitting the stimulatory signals to the catalytic domain. The end-product, however, is common, the second messenger cyclic GMP. Because of the individual signaling mechanisms involved in $\mathrm{Ca}^{2+}$ and hormonal signaling their net effects are multiplicative. Hence, in terms of the original sub-classification, the present day knowledge is that at least two cyclases, ANF-RGC and ONE-GC, are hybrids sensing both hormonal and $\mathrm{Ca}^{2+}$ signals.

The last cloned membrane guanylate cyclase was GC-G. Until today, the information of its function is very scarce. It was suggested that the mouse form of GC-G is selectively expressed in the sperm and may be involved in the process of capacitation (Kuhn et al., 2004). Other reports suggest that the cyclase is expressed in Grueneberg ganglion olfactory subsystem where it is responding to $\mathrm{CO}_{2}$ (Chao et al., 2010) or to cool ambient temperature indicating its role in thermo-sensation (Mamasuew et al., 2008).

The following discussion is exclusively devoted to the ANFRGC. It was the first template model, which established that cyclic GMP is a bona fide hormonal second messenger. The ongoing studies define the second ANF-RGC transduction model, 
$\mathrm{Ca}^{2+}$-modulated signaling. It makes ANF-RGC a bimodal switch, hormonal and $\mathrm{Ca}^{2+}$. An additional significant part of the review is coverage of the manner in which these two models have now begun to explain the biochemical principles of cardiovascular, renal and endocrine homeostasis with special emphasis on blood pressure regulation.

\section{HORMONAL SIGNALING OF ANF-RGC ACTIVATION BINDING OF LIGAND-HORMONE ANF}

Although intuitively expected, the first experimental evidence that the ANF binding site in ANF-RGC is located within the extracellular domain came first from the site-directed and deletion mutagenesis studies. A mutant ANF-RGC was cloned from rat adrenal cDNA library (Duda et al., 1991) and termed GC $\alpha$. Its sequence differed from ANF-RGC by two amino acid substitutions $\mathrm{Q}^{338} \rightarrow \mathrm{H}$ and $\mathrm{L}^{364} \rightarrow \mathrm{P}$ which resulted from single nucleotide mutations, CAG $\rightarrow$ CAC and CTG $\rightarrow$ CCG, respectively. Expressed in heterologous system of COS cells, GC $\alpha$ was properly located in the plasma membrane and exhibited basal guanylate cyclase activity; it however, neither bound nor responded to ANF or other natriuretic peptides (Duda et al., 1991). These results demonstrated that the two amino acid substitutions exclusively abolished binding of ANF and therefore ANF signaling of the cyclase activity. Restoration by site-directed mutagenesis, glutamine at position 338 and leucine at position 364, reinstated ANF binding and ANF-dependent stimulation of the cyclase.

The site of ANF binding was further systematically analyzed (McNicoll et al., 1992, 1996; He et al., 1995; Misono, 2002). By cross-linking and proteinase digestion it was determined that the amino terminus of ANF is in contact with the region $\mathrm{M}^{173}-\mathrm{F}^{188}$ of ANF-RGC, and the C-terminus, with $\mathrm{D}^{191}-\mathrm{R}^{198}$ region. The fact that the identified contact sites were very close to each other was interpreted that the $\mathrm{N}$ - and $\mathrm{C}$ - termini of ANF interface distinct subunits of ANF-RGC homodimer. Importantly, it also implied that one ANF-RGC dimer binds one molecule of ANF.

Details of ANF binding to the ANF-RGC extracellular domain were unraveled by analyses of the extracellular domain of ANFRGC co-crystallized with ANF (Ogawa et al., 2003, 2004). These analyses revealed that (1) the extracellular domain of ANF-RGC exists as a dimer in the head-to-head configuration; (2) one ANFRGC dimer binds one molecule of ANF (2:1 complex); (3) the binding site in one monomer differs from that in the other - one monomer binds the N-terminal part of ANF and the other binds C-terminal part; (4) there is no preference in ANF binding to a specific monomer of the extracellular domain; bound ANF occurs in two alternate orientations of equal occurrence; (5) the membranedistal portion of the extracellular domain contains chloride ion necessary for ANF binding.

\section{TRANSMEMBRANE MIGRATION OF THE ANF BINDING SIGNAL}

With the exception of enterotoxin RGC, all membrane guanylate cyclases contain a hinge region juxtaposed to the $\mathrm{N}$-terminal side of the transmembrane domain. This region contains two conserved cysteine residues separated from each other by $6-8$ residues. In ANF-RGC these residues are $\mathrm{Cys}^{423}$ and $\mathrm{Cys}^{432}$ and were indicated as a critical structural motif in ANF signaling (Huo et al.,
1999; Labrecque et al., 1999; Miyagi and Misono, 2000). There was however no consensus on the mechanism of its operation. Based on results with intact cells transfected with ANF-RGC cDNA it was proposed that the cysteines are involved in dimerization through the formation of an inter-chain S-S bridge (Huo et al., 1999; Labrecque et al., 2001) or, that they form an intra-chain disulfide bridge (Huo et al., 1999; Miyagi and Misono, 2000). Analyses of guanylate cyclase activity in isolated membranes of COS cell expressing $C^{423} S, C^{432} S$, and $C^{423} S, C^{432} S$ mutants (Duda and Sharma, 2005) allowed to conclude that both $C^{423}$ and $C^{432}$ residues independently and equally control the catalytic activity of ANF-RGC and that activation of ANF-RGC does not involve interchain-disulfide bond formation. In the basal state, the disulfide motif keeps the ANF-RGC in its repressed catalytic state and ANF/ATP signaling brings it to the fully active state (Duda and Sharma, 2005).

A model of hormone-induced rotation has been proposed to explain how the extracellular signal is transmitted through the hinge region to the intracellular domain of ANF-RGC (Ogawa et al., 2004; Misono et al., 2005). Binding of ANF causes a twist motion of both ANF-RGC monomers centered on a support point close to the bound ANF. This twist motion translocates the juxtamembrane domains of both monomers with only minimal change in the distance between them. This movement constitutes a signal, which is transmitted through the transmembrane domain. Rotation of the transmembrane domain by 40 degrees occurs in response to ANF binding (Parat et al., 2010).

\section{PASSAGE OF THE ANF SIGNAL THROUGH THE INTRACELLULAR DOMAIN \\ ANF signaling requires ATP}

Early studies, before the biochemical characterization of ANFRGC, demonstrated that activation by ANF is significantly amplified by ATP in the guanylate cyclase activation (Kurose et al., 1987; Cole et al., 1989; Chang et al., 1990; Larose etal., 1991; reviewed in Sharma, 2002; Duda et al., 2005). Subsequently, it was demonstrated that ATP is obligatory for ANF-dependent activation of ANF-RGC (Chinkers et al., 1991; Marala et al., 1991; Goraczniak etal., 1992; Wong et al., 1995; reviewed in Duda et al., 2005). Because the ATP effect was mimicked by its nonhydrolyzable analogs, ATP $\gamma S$ and AMP-PNP, it was suggested that ATP acts as an allosteric regulator (Chinkers et al., 1991; Marala etal., 1991; Goraczniak etal., 1992; Wong et al., 1995; reviewed in Duda et al., 2005). Shortly thereafter it was shown that ATP is also obligatory for the CNP-dependent stimulation of CNP-RGC (Duda et al., 1993a,b). Thus, it appears that the requirement of ATP is a common attribute of natriuretic peptide RGC signaling.

Studies with ANF-RGC deletion mutants revealed that the ATP regulated region resides in the intracellular portion of ANF-RGC between the transmembrane and the C-terminal catalytic domain (Chinkers and Garbers, 1989; Goraczniak et al., 1992). This region was named the kinase homology (or kinase-like domain; KHD or K-LD) because of its sequence similarity with the corresponding domains of tyrosine kinases (Chinkers et al., 1989; Chinkers and Garbers, 1989; Duda et al., 1991). A model for the ATP function was proposed that "binding of ANP to the extracellular domain of 
its receptor initiates a conformational change in the protein K-LD, resulting in de-repression of guanylate cyclase activity" (Chinkers and Garbers, 1989). The central idea behind the model was that KHD in native ANF-RGC suppresses the catalytic module activity; ANF functions by relieving this suppression. Study from our group using two KHD deletion mutants, $\Delta 506-677$ and $\Delta 555$ 762 , negated this model and proposed an alternative one where ATP via ATP regulated module (ARM) potentiates the hormonal signal "(1) the signal is caused by the binding of the hormone to the receptor site; (2) there is a transmembrane migration of the signal; (3) the signal is potentiated by ATP at ARM; and (4) the amplified signal is finally transduced at the catalytic site" (Goraczniak et al., 1992).

\section{ATP allosteric effect and the ARM domain}

Within the KHD ANF-RGC contains a sequence, $\mathrm{G}^{503}-\mathrm{X}-\mathrm{G}^{505}-\mathrm{X}$ $\mathrm{X}-\mathrm{X}-\mathrm{G}^{509}$ (Goraczniak et al., 1992) which is a modified form of the protein kinases' nucleotide-binding consensus sequence G-XG-X-X-G necessary for kinase activity (Wierenga and Hol, 1983; Hanks et al., 1988; Bratová et al., 2005). This motif was probed for its significance in ATP function in ANF signaling. Through analyses of a series of deletion and point mutants it was determined that the $\mathrm{G}^{503}-\mathrm{X}-\mathrm{G}^{505}-\mathrm{X}-\mathrm{X}-\mathrm{X}-\mathrm{G}^{509}$ motif is critical for the ATP function (Goraczniak et al., 1992; Duda et al., 1993a; Duda and Sharma, 1995; reviewed in Sharma, 2002; Duda et al., 2005). Although it is not involved in ATP binding it maintains the steric arrangements to fit the ATP molecule. For this reason, the motif has been named ARM (Goraczniak et al., 1992) and the KHD, where the ARM resides, was termed the ARM domain (Duda et al., 2001b; Sharma et al., 2001). To get an insight into the mechanism of ATP function, the structure of the ARM domain was simulated through computer-assisted homology based modeling (Duda et al., 2001b; Sharma et al., 2001; PDB ID 1T53). The basic structural features of the model have been experimentally validated through point mutation/expression studies (Duda et al., 2001b; Sharma et al., 2001; reviewed in Sharma, 2002; Duda et al., 2005).

Spatial determinants of the ARM domain. The domain comprises amino acid residues $496-771$, which are arranged into two lobes: the smaller, $\mathrm{N}$-terminal (91 aa residues: 496-586), and the larger, C-terminal (185 aa residues: 587-771; Duda et al., 2001b). Four antiparallel $\beta$ strands and one $\alpha$ helix form the smaller lobe; the larger lobe is predominantly helical, composed of eight $\alpha$ helices and two $\beta$ strands (Duda et al., 2001b; Sharma et al., 2001). The ARM motif, $\mathrm{G}^{503}-\mathrm{X}-\mathrm{G}^{505}-\mathrm{X}-\mathrm{X}-\mathrm{X}-\mathrm{G}^{509}$, is located within the smaller lobe.

The ATP-binding pocket. In order to identify the ARM domain residues potentially involved in ATP binding the model of this domain in its ATP-bound form was analyzed (Duda et al., 2005). A radius of $4 \AA$ from the ATP molecule was chosen as the limiting distance for the electrostatic, hydrogen or van der Waals' interactions. Two sets of residues were identified (Figure 4 in reference Duda et al., 2005): (1) those forming the floor of the ATP binding pocket; (2) those surrounding ATP molecule. The residues in the first set are: $\mathrm{G}^{503}, \mathrm{R}^{504}, \mathrm{G}^{505}, \mathrm{~S}^{506}, \mathrm{~N}^{507}, \mathrm{Y}^{508}$, and $\mathrm{G}^{509}$. These residues have no direct chemical interaction with ATP; they, however, provide necessary space to accommodate the ATP molecule. The residues in the second set surround the individual components of ATP, the adenine ring, the ribose ring and the triphosphate moiety. The adenine ring is surrounded by $\mathrm{L}^{511}, \mathrm{~T}^{513}, \mathrm{~T}^{514}, \mathrm{E}^{515}, \mathrm{Q}^{517}$, $\mathrm{A}^{533}, \mathrm{~T}^{580}, \mathrm{E}^{581}, \mathrm{C}^{583}, \mathrm{~V}^{635}$, and $\mathrm{T}^{645}$ and $\mathrm{L}^{511}, \mathrm{~T}^{513}$, and $\mathrm{C}^{583}$ are within a distance shorter than $3 \AA$.

$\mathrm{G}^{503}, \mathrm{~L}^{511}, \mathrm{~T}^{513}, \mathrm{~T}^{514}, \mathrm{G}^{580}, \mathrm{~S}^{587}, \mathrm{D}^{590}$ surround the ribose ring with $\mathrm{L}^{511}$ and $\mathrm{T}^{514}$ located within $2.5 \AA$ radius from the ribose. The phosphate groups are surrounded by $R^{504}, G^{505}, L^{511}, K^{535}, N^{633}$, $\mathrm{D}^{646}$, and $\mathrm{K}^{535}$ is the nearest residue $(2.6 \AA)$ forming a hydrogen bond with the phosphate and has been shown to be critical for ATP regulation of ANF-dependent ANF-RGC activity; $D^{646}$ interacts with the triphosphate group of ATP through the formation of a coordinate bond with the metal ion $\mathrm{Mg}^{2+}$.

Interaction of ATP with the ARM domain. Kinetics of ATP binding to the ARM domain was determined through SPR spectroscopy (Burczynska et al., 2007). AMP-PNP, the non-hydrolyzable analog of ATP was used for the binding studies. Half-maximal binding $\left(\mathrm{EC}_{50}\right)$ occurred when the concentration of AMP-PNP was $\sim 0.2 \mathrm{mM}$ and the calculated $K_{\mathrm{D}}$ value was $0.21 \mathrm{mM}$. Similar results (EC $\mathrm{E}_{50}$ value of $0.15 \mathrm{mM}$ and $K_{\mathrm{D}}$ of $0.13 \mathrm{mM}$ ) were obtained when 8-azido-ATP was used.

The model-predicted ATP binding pocket (vide supra) was authenticated experimentally by cross-linking of the purified isolated ARM domain protein with 8-azido-ATP, trypsin digestion of the cross-linked product and sequencing of the resulting peptides (Burczynska et al., 2007). Three peptides were found to be photoaffinity modified. The longest modified peptide was identified as $\mathrm{G}^{614}$ MLFLHNG-AICSHGNLKSSNCVVDGR ${ }^{639}$ and the shortest as $\mathrm{S}^{631} \mathrm{SNC}^{634} \mathrm{~V}^{635}$ VDGR. In all three peptides Cys ${ }^{634}$ was modified indicating that this residue was the closest to the azido group. The $\mathrm{G}^{614}-\mathrm{R}^{639}$ fragment contains six ATP-binding pocket-predicted residues (Duda et al., 2005): $\mathrm{S}^{625}, \mathrm{~K}^{630}, \mathrm{~S}^{631}, \mathrm{~S}^{632}, \mathrm{~N}^{633}$, and $\mathrm{V}^{635}$; and the shortest $S^{631}-\mathrm{R}^{639}$ fragment contains three residues: $S^{631}$, $\mathrm{N}^{633}$, and $\mathrm{V}^{635}$ (Duda et al., 2005). The refined ARM model (Duda et al., 2005) predicts that $\mathrm{V}^{635}$ is within a $4 \AA$ radius from the adenine ring; cross-linking of the neighboring residue to $\mathrm{C}^{634}$ validates that these residues are indeed the closest to the C- 8 of the adenine ring.

ATP binding dependent changes in the ARM domain. If ATP binding to the ARM domain were to serve signaling purposes, it should induce structural changes that ultimately would signal activation of the catalytic domain. Comparative analyses of the ARM domain models in the apo and ATP-bound states identified such changes. They involve rotations of the $\beta$ strands within the smaller lobe as well as movements of the $\beta$ strands and $\alpha$ helices in the larger lobe (Duda et al., 2001b; Sharma et al., 2001; reviewed in Duda et al., 2005). Consequences of two such changes appear to be of particular importance: first, of the $\beta 1, \beta 2$ strands in the smaller lobe, and the second, of the EF and F helices in the larger lobe.

The $\beta 1$ and $\beta 2$ strands and the loop connecting them encompasses the $\mathrm{G}^{503}-\mathrm{X}-\mathrm{G}^{505}-\mathrm{X}-\mathrm{X}-\mathrm{X}-\mathrm{G}^{509}$ motif (Duda et al., 2001b; Sharma et al., 2001; reviewed in Duda et al., 2005), which is meshed 
in and flanked by six phosphorylation sites, $S^{497}, T^{500}, S^{502}, S^{506}$, $\mathrm{S}^{510}, \mathrm{~T}^{513}$ (Potter and Hunter, 1998a, 1999a). The present consensus is that "phosphorylation of KHD is absolutely required for hormone-dependent activation of NPR-A" (Potter and Hunter, 1998a,b, 1999b). In this concept, hypothetical protein kinase and protein phosphatase co-exist with ANF-RGC (Foster and Garbers, 1998). Until now, however, neither the kinase nor the phosphatase has been identified.

Comparison of the ATP-free and ATP-bound ARM domain models allows explaining how ATP binding makes it possible for the serine and threonine residues to undergo phosphorylation. After ATP binds to the ARM domain, the $\beta 1, \beta 2$ strands, and the loop between them shift by $\sim 3-4 \AA$ and rotate by $\sim 15^{\circ}$ (Duda et al., 2001b; Sharma et al., 2001; reviewed in Duda et al., 2005). This movement triggers reorientation of the serine and threonine residues (Figure 1, red colored residues) causing the side chains and the $\mathrm{OH}$ groups of $\mathrm{T}^{500}, \mathrm{~S}^{502}, \mathrm{~S}^{506}$, and $\mathrm{T}^{513}$ becoming directed toward the protein surface (Figure 1, compare the positions of the cyan- and red-colored $\mathrm{OH}$ groups). The change in the positions of the side chains is most drastic for the $\mathrm{S}^{502}$ and $\mathrm{S}^{506}$ residues. Although upon ATP binding there is no toward the surface reorientation of the $\mathrm{S}^{497}$ and $\mathrm{S}^{510} \mathrm{OH}$ groups, the entire residues are shifted toward the surface (Figure 1). This structural rearrangement permits the hypothetical protein kinase to access the side chains of the residues and transfer the phosphate group (Duda et al., 2011).

Another important result of ATP binding on the dynamics within the ARM domain is the translocation within the larger lobe of two helices, EF and F. Their movement was characterized by analyzing the ATP-dependent changes in the fluorescence intensity and wavelength of two tryptophan residues $\mathrm{W}^{601}$ and $\mathrm{W}^{669}$ (Duda et al., 2009). Both residues reside in the larger lobe of the ARM domain, outside the ATP-binding pocket. The $\mathrm{W}^{601}$ residue is a part of the helix E structure (Duda et al., 2001b, 2005), its side-chain is oriented toward the protein surface, and it is flanked by several hydrophobic residues, $\mathrm{F}^{640}, \mathrm{~L}^{607}, \mathrm{~S}^{606}$, and $\mathrm{S}^{596}$ (Figure 2A). These structural features define the fluorescence $\lambda_{\max }$ of $\mathrm{W}^{601}$ at $332 \mathrm{~nm}$. $\mathrm{W}^{669}$ residue is located at the end of a loop

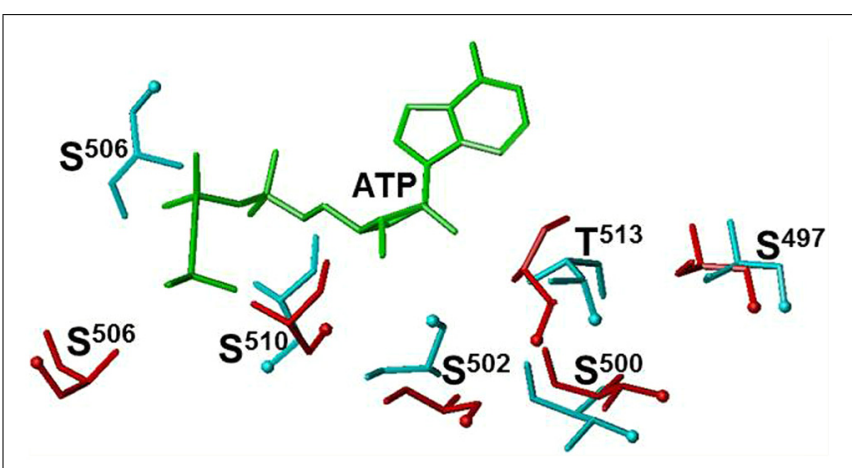

FIGURE 1 | ATP binding to the ARM domain affects the conformation of the six phosphorylable residues. The conformation of the six phosphorylated residues is shown before (cyan) and after (red) ATP binding. The ATP molecule is shown in green. The positions of the $\mathrm{OH}$ groups are indicated by cyan and red balls (reproduced with permission from ref. Duda etal., 2011). connecting $\beta 8$ strand and EF helix (Duda et al., 2009); it is a part of a conserved hydrophobic motif, ${ }^{669}$ WTAPELL ${ }^{675}$. The side chain of $\mathrm{W}^{669}$ is flanked by the polar residues: $\mathrm{E}^{699}, \mathrm{~S}^{631}, \mathrm{~K}^{667}, \mathrm{~K}^{630}$, and $\mathrm{L}^{696}$ (Figure 2B). This environment causes red shifts in the fluorescence $\lambda_{\max }$ of $\mathrm{W}^{669}$ to $345 \mathrm{~nm}$.

Superimposition of the ATP-free and the ATP-bound forms indicates that ATP binding induces contraction of the entire ARM domain and affects the orientation and environment of $\mathrm{W}^{669}$. The contraction results in shortening of the distance between $\mathrm{W}^{669}$ and the ATP binding pocket (Figure 2C). ATP binding also causes reorientation of the $\mathrm{W}^{669}$ side chain. It turns and becomes more shielded by the surrounding amino acids. Turning of the $\mathrm{W}^{669}$ side chain pushes the remainder of the motif, ${ }^{670}{ }^{\text {TAPELL }}{ }^{675}$, to the surface resulting in its exposure. In general, the movement of a hydrophobic motif toward the surface of the protein indicates its readiness for interaction. For the ${ }^{669}$ WTAPELL ${ }^{675}$ motif it was proposed that it interacts with subsequent transduction motif, possibly within the catalytic domain, propagates the ANF/ATP binding signal and activates the catalytic domain (Duda et al., 2009).

Based on the studies narrated above a model for ANF/ATP signaling of ANF-RGC activity was proposed: The ANF signal originates by the binding of one molecule of ANF to the extracellular dimer domain of ANF-RGC (Ogawa et al., 2004, 2009). The binding modifies the juxtamembrane region where the disulfide ${ }^{423}$ Cys-Cys ${ }^{432}$ structural motif is a key element in this modification (Ogawa et al., 2004, 2009; Duda and Sharma, 2005). The signal twists the transmembrane domain (Parat et al., 2010), induces a structural change in the ARM domain, and prepares it for the ATP activation. ARM domain binds ATP to its pocket what leads to a cascade of temporal and spatial changes (Duda et al., 2001b; Sharma et al., 2001; reviewed in Duda et al., 2005). They result in (1) exposure of the hydrophobic ${ }^{669}$ WTAPELL ${ }^{675}$ motif which directly (or indirectly) interacts with the catalytic domain causing its partial activation; and (2) exposure and phosphorylation of six serine, threonine residues and full activation of ANF-RGC. Concomitantly, phosphorylation converts ATP binding site from the high to low affinity, ATP dissociates and ANF-RGC returns to its ground state (Duda et al., 2011).

\section{CATALYTIC DOMAIN}

When more then 20 years ago an ANF RGC was purified to homogeneity and shown to contain the ANF binding and cyclic GMP forming activities on the same protein chain, the authors proposed a topological model for the transmembrane receptor enzyme in which the receptor part was extracellular and the cyclase catalytic domain was intracellular (Sharma et al., 1988a,b). The cloning studies confirmed this prediction. Alignment of the deduced amino acid sequences of the cloned guanylate cyclases indicated that the catalytic domain is located at the C-terminus of ANF-RGC and comprises 239 amino acid residues (Chinkers et al., 1989; Duda et al., 1991). This prediction was tested experimentally (Thorpe and Morkin, 1990; Thorpe et al., 1996). The carboxy terminal 293 amino acids fragment of ANF-RGC was expressed as a soluble protein and shown to exhibit guanylate cyclase activity. These results were in agreement with studies that determined through radiation inactivation experiments that the ANF-RGC 

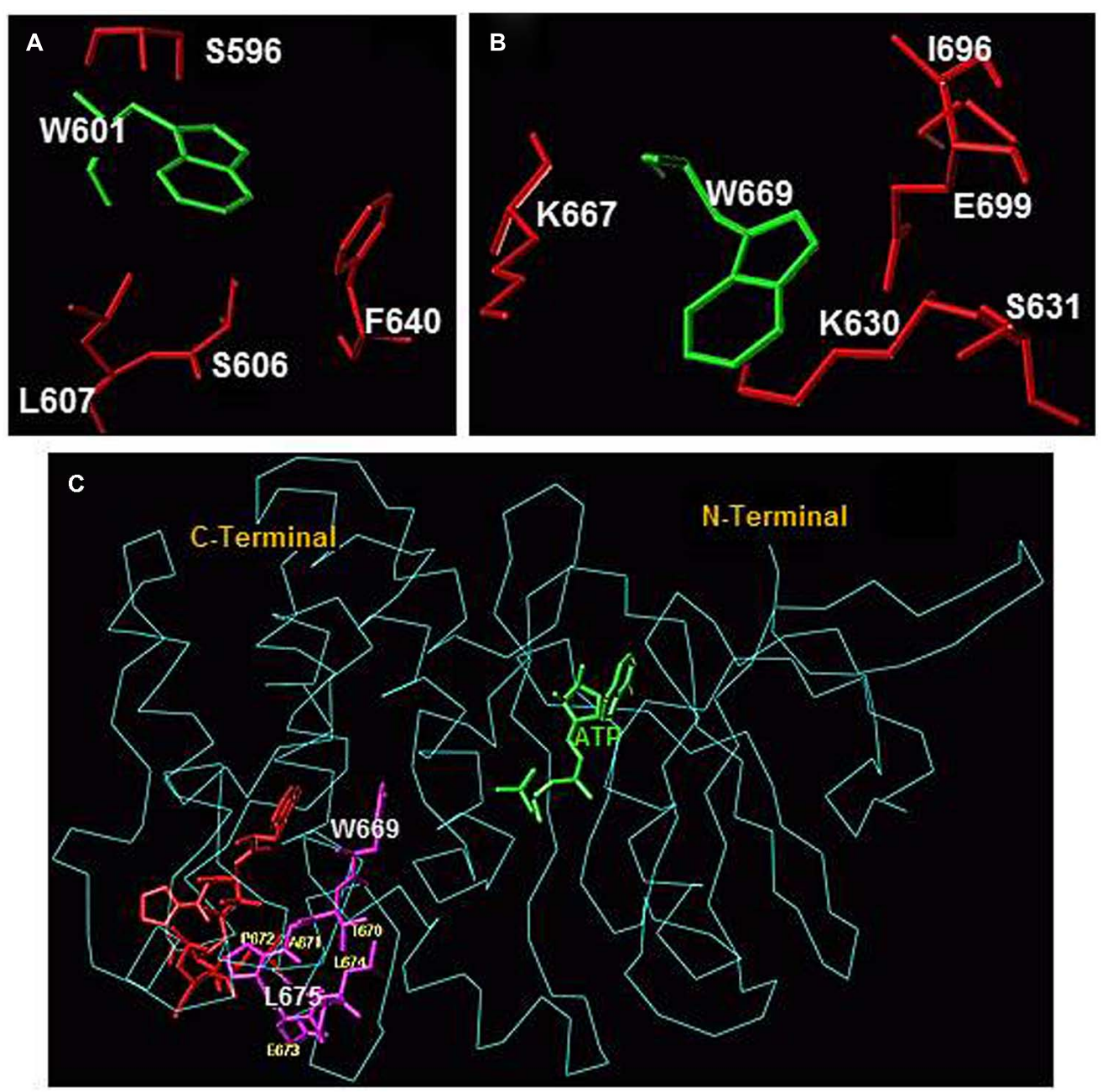

FIGURE 2 I (A) Amino acid residues surrounding $W^{601}$ and (B) amino acid residues surrounding $W^{669}$ within the ARM domain. Amino acid residues depicted in red are located within a $4 \AA$ sphere from the respective tryptophan residue (green). (C) Conformational changes within the ${ }^{669}$ WTAPELL ${ }^{675}$ motif induced by ATP binding to the ARM domain. The backbone structure of the ATP-bound ARM domain is shown in cyan and the ATP molecule is in green. The 669WTAPELL 675 motif is shown in magenta color. Apo structure of the ARM domain was superimposed on the ATP-bound form to assess the relative, ATP binding induced,

conformational changes. For clarity, only the ${ }^{669}$ WTAPELL ${ }^{675}$ motif (shown in red) of the apo-enzyme is visible. ATP binding results in a more compact structure of the ARM domain: the $\mathrm{W}^{669}$ side chain moves toward the ATP binding pocket while the side chains of $T^{670}, E^{673}, L^{674}$, and $L^{675}$ move toward the protein surface [compare the orientation of side chain of these amino acid residues before (in red) and after (in magenta) ATP binding; fonts for $W^{669}$ and $L^{675}$ residues are increased for better visibility]. This movement changes the surface properties of the ARM domain. The movement toward the surface of the protein is poised to facilitate interaction of this amino acid stretch with subsequent transduction motif, possibly within the catalytic domain, propagation of the ANF/ATP binding signal and activation of the catalytic domain (reproduced with permission from ref. Duda etal., 2009). fragment containing cyclase activity has a molecular weight of $32 \pm 8 \mathrm{kDa}$ (Tremblay et al., 1991). Further studies identified several residues within this region that appeared to be critical for the guanylate cyclase activity: $\mathrm{L}^{817}$ (Miao et al., 1995), $\mathrm{D}^{877}, \mathrm{~K}^{887}$, $\mathrm{D}^{893}, \mathrm{G}^{900}, \mathrm{H}^{909}, \mathrm{R}^{940}$, and $\mathrm{H}^{944}$ (Thompson and Garbers, 1995). Their individual mutations to Ala resulted in ANF-RGC mutants without detectable guanylate cyclase activity. In contrast to these residues, mutation of $\mathrm{E}^{974}$ to Ala resulted in a hyperactive ANFRGC mutant (Wedel et al., 1997). Based on these results it was concluded that the indicated residues are located within or close to the catalytic center or are critical for the proper folding of the catalytic center.
In the absence of a crystal structure of any membrane guanylate cyclase catalytic domain a model of the catalytic center of retGC-1, a mammalian membrane guanylate cyclase expressed in the retina, also known as ROS-GC1 was proposed (Liu et al., 1997). The model was built based on homology with the catalytic center of the adenylate cyclase. The modeling studies allowed identification of the critical residues constituting the catalytic core. Because the catalytic domains of all membrane guanylate cyclases are highly conserved ( $>95 \%$ of sequence identity), by homology substitution, the critical residues of the ANFRGC catalytic center have been identified and they are described below. 
The catalytic center is homodimeric. There are two GTP binding sites. Each GTP molecule interacts with both monomers. In the following description of the ANF-RGC catalytic center the monomers are labeled " $\mathrm{A}$ " and " $\mathrm{B}$ " and the location of each residue within a monomer $\mathrm{A}$ or $\mathrm{B}$ is indicated. Numbering of amino acids is according to the mature protein (Duda et al., 1991). $\mathrm{R}^{959}(\mathrm{~B})$ and $\mathrm{C}^{961}(\mathrm{~B})$ interact with guanine's $\mathrm{O6}$; second $\mathrm{NH}_{2}$ group of $\mathrm{R}^{959}(\mathrm{~B})$ interacts with guanine's $\mathrm{N} 1$; the carboxy group of $\mathrm{E}^{889}(\mathrm{~B})$ interacts with $R^{959}(B)$ and through it with $N 1 ; G^{964}(B)$ interacts with N7; $\mathrm{T}^{854}(\mathrm{~A}), \mathrm{D}^{893}(\mathrm{~A})$ and $\mathrm{N}^{968}(\mathrm{~B})$ form hydrogen bonds with ribose's $\mathrm{OH}\left(3^{\prime}\right)$ group; $\mathrm{R}^{972}\left(\mathrm{~B}\right.$ binds $\alpha$ phosphate group; $\mathrm{R}^{940}(\mathrm{~A})$ binds $\beta$ phosphate group; $\mathrm{E}^{974}(\mathrm{~A})$ through $\mathrm{Mg}^{2+}$ interacts with $\beta$ phosphate group; and $S^{971}(\mathrm{~A})$ binds $\gamma$ phosphate group. Specificity toward GTP is determined by $E^{889}$ and $C^{961}$ of ANF-RGC. This conclusion is drawn based on studies showing that in ROS-GC1 mutation of the corresponding $\mathrm{E}$ to $\mathrm{K}$ and $\mathrm{C}$ to $\mathrm{D}$ converts guanylate cyclase activity into adenylate cyclase activity (Tucker et al., 1998).

\section{Mechanism of ANF-RGC activation - the role of the ${ }^{669}$ WTAPELL ${ }^{675}$ motif}

An important feature of the model of ANF/ATP-dependent activation of ANF-RGC is the relay function of the ${ }^{669}$ WTAPELL $^{675}$ motif. It switches between the ATP-bound ARM domain and activates the catalytic domain. It was proposed that this motif interacts with and signals the antiparallel homo-dimer of the catalytic domain to undergo conformational changes and form a functional catalytic center (Duda et al., 2009). The exact site within the catalytic domain which is targeted by the ${ }^{669}{ }^{\text {WTAPELL }}{ }^{675}$ motif remains to be determined. Preliminary scanning experiments, however, suggest that the site may be located close to the $\mathrm{E}^{889}$, a residue critical for cyclase specificity toward GTP (Tucker et al., 1998).

If the elements of the model are correct and the ${ }^{669}$ WTAPELL $^{675}$ motif is a switch, its deletion from the ANF-RGC should lead to a protein which binds ANF and ATP but is not able to respond to them with increased synthesis of cyclic GMP. This assumption was tested experimentally. An ANF-RGC mutant was created in which the ${ }^{669}$ WTAPELL ${ }^{675}$ motif was deleted by mutagenesis. Wild type ANF-RGC and the mutant were expressed individually in COS cells and their membranes were analyzed (1) by Western blot to determine the proteins' levels of expression; (2) for basal guanylate cyclase activity; (3) for ANF binding; and (4) for $\mathrm{K}_{\mathrm{M}}$ for the substrate GTP. The results demonstrated that (1) the wild type ANF-RGC and the ${ }^{669}{ }^{6 T A P E L L}{ }^{675}$ deletion mutant were expressed to the same level as determined by Western blot; (2) the basal cyclase activity of the mutant, 20 pmol cGMP $\min ^{-1}$ (mg protein $)^{-1}$, was virtually identical to that of the wild type ANFRGC, 21 pmol cGMP $\min ^{-1}$ (mg protein) ${ }^{-1}$; (3) their receptor activities were equal with the respective specific binding values of $9.7 \pm 0.6$ and $10.1 \pm 0.9 \mathrm{pmol}\left[{ }^{125} \mathrm{I}\right] \mathrm{ANF} / \mathrm{mg}$ protein and (4) the $\mathrm{K}_{\mathrm{M}}$ values for the substrate GTP, $614 \mu \mathrm{M}$ for the wild type and $608 \mu \mathrm{M}$ for the mutant protein were identical. Thus, the basal integrity of the protein remained intact despite the deletion (Duda et al., 2009).

When the mutant was exposed to increasing concentrations of ANF and ATP its cyclase activity remained practically unchanged whereas under identical conditions wild type ANF-RGC was stimulated over 6-fold (Duda et al., 2009, 2013) demonstrating that in line with the original expectations the catalytic domain does not increase cyclic GMP synthesis in the presence of ANF/ATP. This type of outcome could only be observed if the mutant protein did not bind ANF and/or ATP or the catalytic domain lost its cyclase ability. Both of these possibilities were put to rest as the mutant and the wild type cyclase did not differ in ANF and ATP binding nor in enzymatic activity (vide supra and ref. Duda et al., 2009). Therefore the only explanation for the unchanged level of cyclic GMP synthesis is that the ${ }^{669}$ WTAPELL $^{675}$ deletion mutant is not able to respond to ANF and ATP. This leads to just one logical conclusion that in the absence of the ${ }^{669}$ WTAPELL ${ }^{675}$ motif the ANF/ATP binding information is not transmitted to the catalytic domain. Thus, the ${ }^{669}$ WTAPELL $^{675}$ motif is the critical transmitter of the ATP-potentiated ANF signal to the catalytic domain where it is translated into generation of cyclic GMP.

\section{$\mathrm{Ca}^{2+}$ SIGNALING OF ANF-RGC ACTIVITY NEURONAL CALCIUM SENSOR NEUROCALCIN $\delta$}

Neurocalcin $\delta$ belongs to a distinct subfamily of neuronal calcium sensor proteins (NCS) together with visinin-like proteins (VILIPs) and hippocalcin. They all are acylated at the N-terminus by myristic acid and undergo a classical calcium-myristoyl switch (Ladant, 1995), e.g., they bury the myristoyl group in a hydrophobic pocket in $\mathrm{Ca}^{2+-}$ free form and expose it in $\mathrm{Ca}^{2+}$-bound form, as first observed and described for recoverin (Zozulya and Stryer, 1992). Exposure of myristoyl group enables the protein association with the cell membrane. However, once it binds, in a $\mathrm{Ca}^{2+}$-dependent fashion, to the membrane phospholipids, even after removing $\mathrm{Ca}^{2+}$ by the addition of EGTA part of it remains membrane bound (Krishnan et al., 2004). Although NC $\delta$ is primarily expressed in neuronal tissues, its expression in the periphery is also observed.

Functionally, NC $\delta$ has been linked to receptor endocytosis through interaction with $\alpha$ - and $\beta$-clathrin and $\beta$-adaptin (Ivings et al., 2002), trafficking and membrane delivery of glutamate receptors of the kainate type (Coussen and Mulle, 2006), and due to its $\mathrm{Ca}^{2+}$-dependent affinity for $\mathrm{S} 100 \mathrm{~B}$ protein and tubulin $\beta$ chain (Okazaki et al., 1995), with microtubule assembly (Iino et al., 1995). In the sensory and sensory-linked neurons, the presence of NC $\delta$ has been found in the inner plexiform layer of the retina, e.g., in the amacrine and ganglion cells (Krishnan et al., 2004), olfactory sensory neurons (Duda et al., 2001a, 2004) and recently, it has been identified in type II cells of mouse circumvallate taste papillae, indicating its possible role in gustatory transduction (Rebello et al., 2011).

A relatively newly identified function of NCS is its $\mathrm{Ca}^{2+}$ dependent modulation of the activities of membrane guanylate cyclases ROS-GC1 in the retina and ONE-GC, in the olfactory neuroepithelium (Duda et al., 2001b, 2004; Krishnan et al., 2004). In these tissues $\mathrm{NC} \delta$ co-localizes with its respective target cyclases. The exact physiological significance of the ROS-GC1- NC $\delta$ signaling system in the retinal neurons is not known yet. It can be, however, safely stated that the pathway is not present in the rod and cone outer segments, thus is not linked with the phototransduction machinery. The system has been localized to the lower strata 
of the inner plexiform layer and to a subpopulation of ganglion cells (Krishnan et al., 2004).

In the olfactory neuroepithelium NC $\delta$ serves as a $\mathrm{Ca}^{2+}$ sensor component of the two-step odorant uroguanylin signaling machinery. This signaling mechanism was proposed to be initiated by uroguanylin interaction with the extracellular receptor domain of ONE-GC (Leinders-Zufall et al., 2007; Duda and Sharma, 2008; reviewed in Zufall and Munger, 2010; Sharma and Duda, 2010). This interaction leads to partial activation of ONE-GC, generation of small amount of cyclic GMP, partial opening of cyclic GMP-gated channel and influx of $\mathrm{Ca}^{2+}$ into the olfactory receptor neuron. In the next step, $\mathrm{Ca}^{2+}$ binds to NC $\delta$ which, then fully activates ONE-GC (Duda and Sharma, 2009).

\section{FREE $\mathrm{Ca}^{2+}$ SIGNALS ANF-RGC ACTIVATION}

In the course of mapping the NC $\delta$ targeted site on ROS-GC1 to which it binds and transmits the $\mathrm{Ca}^{2+}$ signal to the catalytic domain for signal translation into the generation of cyclic GMP, our group made a remarkable observation that NC $\delta$ binds directly to the catalytic domain and, thereby, activates ROS-GC1 (Venkataraman et al., 2008). Protein database comparison shows sequence conservation of the catalytic domain in the membrane guanylate cyclase family hinting at a possibility that other membrane guanylate cyclases might be activated by $\mathrm{Ca}^{2+}$ via $\mathrm{NC} \delta$ as well. To test this possibility, ANF-RGC membrane guanylate cyclase, for which the only established signal transduction mechanism was through ANF/ATP (vide supra), was chosen. And indeed, in a recombinant system, myristoylated $\mathrm{NC} \delta$ stimulated ANF-RGC activity in a dose- and $\mathrm{Ca}^{2+}$-dependent manner; $0.5 \mu \mathrm{M} \mathrm{Ca}{ }^{2+}$ and $0.5 \mu \mathrm{M}$ NC $\delta$ triggered half-maximal activation of ANF-RGC (Duda et al., 2012a,b). These results for the first time demonstrated that ANF-RGC activity is dually regulated, by peptide hormones $\mathrm{ANF}$ and $\mathrm{BNP}$, and by $\mathrm{Ca}^{2+}$, thus, at least in vitro the cyclase was deemed a bimodal signal transducer.

\section{Myristoylated dimeric form of neurocalcin $\delta$ is the transmitter of the Ca' ${ }^{2+}$ signal}

Since NC $\delta$ belongs to the family of NCS and myristoylation at $\mathrm{N}$-terminus is a characteristic feature of a majority, but not all, of these proteins important for their cellular function, it was necessary to check whether myristoylation was required for NC $\delta$ to transmit the $\mathrm{Ca}^{2+}$ signal for ANF-RGC activation. Reconstitution experiments of ANF-RGC with both myristoylated and non-myristoylated NC $\delta$ showed that only the myristoylated NC $\delta$ stimulated the cyclase activity whereas the non-myristoylated form was ineffectual (Duda etal., 2012b). Importantly, both forms exhibited comparable affinity for ANF-RGC. In addition to activating ANF-RGC myristoylated NC $\delta$ also lowered the cyclase's $\mathrm{K}_{\mathrm{M}}$ for substrate GTP and increased its catalytic efficiency, $k_{\text {cat }}$, from $6.5 \pm 0.3$ to $41.4 \pm 0.5 \mathrm{pmol}$ cyclic $\mathrm{GMP} / \mathrm{s}$.

The biochemical and homology based modeling studies indicate that the secondary structure of the functional form of all membrane guanylate cyclases is homodimeric (Rondeau et al., 1995; Liu etal., 1997; Venkataraman etal., 2008). The contact points for their homo-dimeric formation reside in their extracellular domain (Misono et al., 2011) and in the intracellular domain within the highly conserved dimerization domain (Wilson and
Chinkers, 1995) and core catalytic core domain (Venkataraman et al., 2008). The X-ray crystallographic studies have demonstrated that NC $\delta$ also exists as a dimer (Vijay-Kumar and Kumar, 1999). Thus, it was reasonable to expect that the $\mathrm{Ca}^{2+}$-modulated functional unit is NC $\delta$ dimer and ANF-RGC dimer.

This expectation was validated experimentally. When monomeric and dimeric forms of myristoylated NC $\delta$ were individually tested in reconstitution experiments for their abilities to stimulate ANF-RGC catalytic activity only the dimer was effective (Duda et al., 2012b). The stimulation by the monomeric form was only marginal, possibly resulting from spontaneous dimerization of the monomers when higher NC $\delta$ concentrations were used (Duda et al., 2012b). Thus indeed the functional $\mathrm{Ca}^{2+}$ signal transduction unit is composed of one $\mathrm{NC} \delta$ dimer and one ANF-RGC dimer.

\section{Neurocalcin $\delta$ targets directly the catalytic domain of ANF-RGC}

The ANF-RGC fragment, aa 788-1029, encompassing the core catalytic domain, $I^{820}-G^{1029}$, was expressed as a soluble protein and tested for its basal and $\mathrm{Ca}^{2+}$-dependent modulated via $\mathrm{NC} \delta$ activities. The protein exhibited intrinsic guanylate cyclase activity $\left(18 \pm 4\right.$ pmol cyclic GMP $\min ^{-1} \mathrm{mg}$ protein $\left.{ }^{-1}\right)$. This activity increased when $\mathrm{Ca}^{2+}$ and $\mathrm{NC} \delta$ were added, and the increase was $\mathrm{Ca}^{2+}$ and NC $\delta$-dose dependent (Duda et al., 2012b). Interestingly, the estimated $\mathrm{EC}_{50}$ for $\mathrm{NC} \delta$ was comparable to that determined for full-length ANF-RGC strongly supporting the expectation that the NC $\delta$ signaling site resides within the catalytic domain.

The NC $\delta$ targeted site on ROS-GC1 was mapped to the aa segment $\mathrm{V}^{837}-\mathrm{L}^{858}$. The corresponding site on ANF-RGC, ${ }^{849}$ DIVGFTALSAESTPMQVVTLLMQ ${ }^{871}$, has $70 \%$ sequence conservation in comparison with ROS-GC1. When a synthetic peptide of this sequence was used in a functional interference experiment almost complete inhibition of the NC $\delta$-stimulated ANF-RGC activity at $200 \mu \mathrm{M}$ with an $\mathrm{IC}_{50}$ value of $80 \mu \mathrm{M}$ was observed (Duda et al., 2012b). Because a scrambled peptide did not exhibit any inhibitory effect it was justified to conclude that the ANF-RGC region ${ }^{849}$ DIVGFTALSAESTPMQVVTLLMQ ${ }^{871}$ mediates NC $\delta$ dependent $\mathrm{Ca}^{2+}$ stimulation of ANF-RGC activity. This region is a part of the core catalytic domain and common to the corresponding sites in other membrane guanylate cyclases ${ }^{28}$, it has a secondary structure of helix-loop-helix and is acidic in nature with a pI of 3.37 (Duda et al., 2012b).

\section{The effects of ANF/ATP and $\mathrm{Ca}^{2+}$-neurocalcin $\delta$ signaling of ANF-RGC activity are multiplicative}

To determine the liaison between ANF/ATP and $\mathrm{Ca}^{2+}{ }_{-} \mathrm{NC} \delta$ signaling modes, ANF-RGC activity was analyzed first in the presence of $1 \mu \mathrm{M} \mathrm{Ca}^{2+}$ and $2 \mu \mathrm{M}$ myristoylated $\mathrm{NC} \delta$ and then with increasing concentrations, ranging from $10^{-11} \mathrm{M}$ to $10^{-6} \mathrm{M}$, of ANF and constant $0.8 \mathrm{mM}$ ATP. The presence of $\mathrm{Ca}^{2+}$ and NC $\delta$ resulted in stimulation of the cyclase activity approx. 3.5fold above the basal activity. Addition of ANF and ATP resulted in additional 4.5 -fold stimulation, demonstrating that the $\mathrm{Ca}^{2+}-\mathrm{NC} \delta$ and ANF/ATP effects are multiplicative (Duda et al., 2012b). It is noteworthy that in the absence of $\mathrm{Ca}^{2+}$ in the reaction mixture only the ANF/ATP-dependent stimulation of ANF-RGC activity was observed. 
The preceding narration on the mechanisms involved in the hormone- or $\mathrm{Ca}^{2+}-\mathrm{NC} \delta$-dependent stimulation of ANF-RGC activity explains the independence and multiplicativeness of the ANF and $\mathrm{Ca}^{2+}-\mathrm{NC} \delta$ signals in the activation of ANF-RGC. It is based on our evolving conceptual scheme whose central idea is that the functional specificity of a guanylate cyclase is determined by the structure of its modular blocks. The structural motif, ${ }^{669}$ WTAPELL ${ }^{675}$ is involved in transmitting the ANF signal to the catalytic domain (Duda et al., 2009) but it is not involved in transmitting the $\mathrm{Ca}^{2+}$ signal to the catalytic domain; instead the ${ }^{849}$ DIVGFTALSAESTPMQVVTLLMQ $^{871}$ motif is involved (Duda et al., 2012b).

\section{PHYSIOLOGICAL VALIDATION OF THE TWO SIGNALING MECHANISMS OF THE ANF-RGC ACTIVATION}

The two described above signaling mechanisms of ANF-RGC activation are depicted in Figure 3. It is obvious from their description that they were developed based solely on biochemical observations. And although biochemically well-proven, they would have to be considered only hypothetical until their validity was confirmed in vivo. And this validation is narrated below.

\section{SIGNALING THROUGH THE ${ }^{669}$ WTAPELL ${ }^{675}$ MOTIF}

In an in vitro reconstituted system the ${ }^{669}{ }^{\text {WTAPELL }}{ }^{675}$ motif is critical for the transmission of the ANF/ATP signal and activation of the ANF-RGC catalytic domain and its absence results in unresponsiveness of the mutated ANF-RGC to the signal so if the same happens in vivo, an animal model in which the sequence coding for the ${ }^{669}$ WTAPELL $^{675}$ motif is deleted from the ANFRGC gene should be unresponsive to ANF and therefore exhibit all physiological consequences of this unresponsiveness. Following this logic, the ${ }^{669}$ WTAPELL $^{675}$ sequence was deleted in genetically altered mice (Duda et al., 2013). It is worth mentioning that up till now it is the only ANF-RGC domain-specific genetically modified animal model.

In agreement with the in vitro determinations, basal ANF-RGC activity in the membranes of the heart, adrenal gland and kidney, the primary tissues where ANF-RGC is expressed, was practically indistinguishable between the wild type control (ANF-RGC ${ }^{669}$ WTAPELL $^{675+/+}$ ), heterozygous (ANF-RGC ${ }^{669}$ WTAPELL $^{675+/-}$ ) and homozygous (ANFRGC $^{669}$ WTAPELL $^{675-/-}$ ) mice (Duda et al., 2013). However, the mutated cyclase expressed in these tissues did not respond to ANF/ATP stimulation. The cyclase activity in the membranes of the homozygous mice was the same when assayed in the presence of $10^{-7} \mathrm{M}$ ANF and $0.8 \mathrm{mM}$ ATP as when assayed in their absence. Interestingly, for the heterozygous mice, the cyclase remained responsive to ANF/ATP but the maximal achieved activity oscillated around $50 \%$ of the wild type values, clearly showing that in the heterozygous mice where the product of one ANF-RGC gene copy is of the wild type and the other, of the deletion-mutated cyclase, only the wild type ANF-RGC is responsive to ANF/ATP
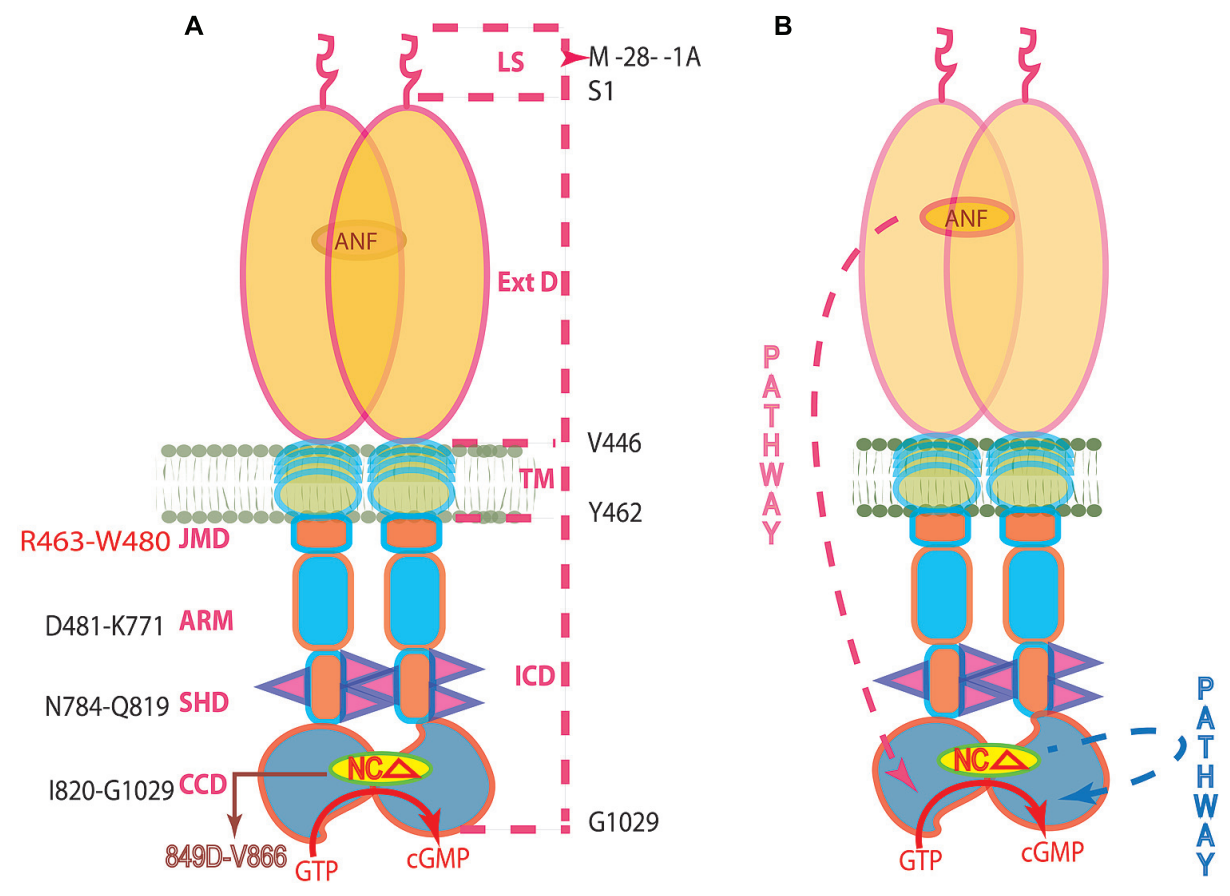

FIGURE 3 | (A) Topography of ANF-RGC. The dashed lines on the right show the boundaries of: LS, leader sequence; ExtD, extracellular domain; TM, transmembrane domain; ICD, intracellular domain. The functional domains in $I C D$, their names and the aa constituting their boundaries are indicated the left: JMD, juxtamembrane domain; ARM, the ATP regulated module; SHD-signaling helix domain; CCD-core catalytic domain. The site targeted by
NCS (encircled) is within CCD. (B) The signaling pathways of ANF and of NC $\delta$ are independent. The trajectory of the ANF pathway is in red dashed arrow. From the ExtD, it passes through the TM, ARM and SHD in its course to CCD. The trajectory of the NC $\delta$ pathway (in blue dashed arrow) is within the CCD. The CCD exists as an antiparallel homodimer (reproduced with permission from ref. Duda etal., 2012b). 
and the mutant is not (Duda et al., 2013). Thus, the in vitro activity characteristics were the mirror images of these in vivo.

Almost identical values of basal guanylate cyclase activity in various tissues of the ${ }^{669}$ WTAPELL $^{675}$ targeted mice and their isogenic controls implied that the expression of the mutant-cyclase must not differ from the expression of the wild type cyclase. This implication was confirmed by the results of immunocytochemical analyses. Side-by-side immunostaining with immunopurified anti ANF-RGC antibody resulted in identical images of the kidneys and adrenal glands of the wild type, heterozygous and homozygous ${ }^{669}$ WTAPELL ${ }^{675}$ targeted mice. Also, visual examination of the stained sections as well as of the respective differential interference contrast images indicated that the targeting of the ${ }^{669}$ WTAPELL $^{675}$ motif does not change the integrity of these tissues (Duda et al., 2013).

The main function of ANF/ANF-RGC signaling system is to regulate natriuresis, diuresis, vasodilation, and prevent cardiac and renal hypertrophy. It regulates blood volume homeostasis and blood pressure by off-setting the renin-angiotensin-aldosterone system (RAAS): inhibiting renal renin secretion and aldosterone synthesis in the adrenocortical zona glomerulosa (Burnett et al., 1984; Brenner et al., 1990; Maack, 1996; Olson et al., 1998; Aoki et al., 2000; Shi et al., 2001). Therefore, elimination of ANF-RGC signaling through knocking-out either ANF-RGC or ANF gene leads to increased blood pressure, cardiac, and renal hypertrophy, fibrosis, to name some of the related pathological conditions (Dubois et al., 2000; Kishimoto et al., 2001; Ellmers et al., 2007; Das et al., 2010; Ellis et al., 2011; Pandey, 2011; Wadei and Textor, 2012). Since the ${ }^{669}$ WTAPELL ${ }^{675}$ targeted mice have partially (heterozygous) and fully (homozygous) suppressed ANF-RGC response to ANF, but the basal cyclase activity is unaffected the critical question was: does this suppression lead to increased blood pressure and other physiological alterations in the genetically modified mice?

The answer obtained was clearly "yes." In comparison with the wild type the blood pressure of the heterozygous mice increased by $\sim 37 \%$ and of the homozygous mice by $\sim 56 \%$. The increase was statistically highly significant with $P$ value $<0.005$ (Duda et al., 2013). It rose from $102 \pm 9 \mathrm{~mm} \mathrm{Hg}$ for the wild type mice to $134 \pm 17 \mathrm{~mm} \mathrm{Hg}$ for the heterozygous and $159 \pm 11 \mathrm{~mm} \mathrm{Hg}$ for the homozygous mice. These values showed that the progressive elevation of blood pressure directly correlates with the number of mutated ANF-RGC gene copies.

Because volume homeostasis and blood pressure are influenced by the mineralocorticoid hormone aldosterone secreted by the cells of the adrenocortical zona glomerulosa and the function of the ANF/ANF-RGC system is to inhibit this synthesis the obvious next question was whether the increased blood pressure in the ${ }^{669}$ WTAPELL ${ }^{675}$ targeted mice is a consequence of the inability of the mutated ANF-RGC to transduce the ANF signal and to synthesize cyclic GMP sufficient quantities to inhibit aldosterone synthesis? A hint was provided by studies on ANF-RGC knockout mice showing that these mice had increased aldosterone level (Zhao et al., 2007).

The plasma aldosterone concentrations were measured in both types of genetically modified mice (hetero- and homozygous) and in their isogenic controls (wild type). The results demonstrated that, in comparison with the wild type mice, the plasma aldosterone concentration increased by approximately $40 \%$ (from $147 \pm 12$ to $204 \pm 18 \mathrm{pg} / \mathrm{ml}$ ) in the plasma of the heterozygous mice $(P<0.005)$ and by approximately $75 \%$ (up to $256 \pm 22 \mathrm{pg} / \mathrm{ml})$ in the plasma of the homozygous mice $(P<0.005)$ (Duda et al., 2013).

Chronic pressure overload is almost always accompanied by cardiac hypertrophy (reviewed in Katholi and Couri, 2011). The same is observed in the ${ }^{669}$ WTAPELL $^{675}$ targeted mice. The ratio of the heart weight (in $\mathrm{mg}$ ) to whole body weight (in g) measured in 12 weeks old mice was $5.6 \pm 0.3$ and $6.1 \pm 0.5$ for the ${ }^{669}$ WTAPELL $^{675(+/-)}$ and ${ }^{669}$ WTAPELL $^{675(-/-)}$ mice, respectively, whereas it was $5 \pm 0.3$ for the wild type mice (Duda et al., 2013). However, hypertension is not the only cause of myocardial hypertrophy. Using animal models it has been shown that antihypertensive drugs do not always ameliorate cardiac hypertrophy (Knowles etal., 2001) and that even without systemic hypertension cardiac hypertrophy may occur (Oliver et al., 1997; Holtwick et al., 2003). Because deletion of the ${ }^{669}{ }^{\text {WTAPELL }}{ }^{675}$ motif from ANF-RGC results in decreased synthesis of cyclic GMP it was hypothesized that cardiomyocytes of the ${ }^{669}$ WTAPELL $^{675}$ targeted mice succumb to the insufficient quantities of cyclic GMP and normal inhibition of myocardial proliferative responses does not occur. Our ongoing studies indicate that indeed it is the case. The mice as young as 3 weeks of age (at weaning) exhibit significant cardiac hypertrophy. Which cyclic GMPdependent signaling pathway involved in inhibition of myocardial proliferative responses is affected in these mice remains to be determined.

Taken together the biochemical and physiological evidence prove that the ${ }^{669}$ WTAPELL $^{675}$ motif is critical for the ANF-RGC function as the transducer of the ANF/ATP signal.

\section{NEUROCALCIN $\delta \mathrm{Ca}^{2+}$-DEPENDENT SIGNALING OF ANF-RGC}

To demonstrate that the ANF-RGC NC $\delta-\mathrm{Ca}^{2+}$ signal transduction system is functional in vivo a mouse model with a disrupted NC $\delta$ gene was constructed and analyzed. Unfortunately, disruption of both copies of NC $\delta$ gene is lethal. Although it was unexpected at the time of developing the mouse line, it can be now understood in view of the results demonstrating that NC $\delta$ may be involved in spermatogenesis. Therefore, heterozygous, $\mathrm{NC}^{+/-}$, line is viable.

Because earlier studies from our laboratory and others' had shown that NC $\delta$ is expressed in the adrenocortical zona glomerulosa (Nakano et al., 1993; Duda et al., 2012a) and that the adrenal gland also contains functional ANF-RGC transduction system (Takayanagi et al., 1987; Sharma etal., 1989; Duda etal., 1991; Rondeau et al., 1995) the adrenal gland appeared to be the tissue of choice for testing whether the ANF-RGC NC $\delta-\mathrm{Ca}^{2+}$ signal transduction system is operational and of physiological significance there.

To show that NC $\delta$ is indeed the $\mathrm{Ca}^{2+}$-sensor modulator of ANF-RGC in the adrenal gland the particulate fractions of the adrenal glands from wild type and $\mathrm{NC}^{+/-}$mice and their isogenic controls $\left(\mathrm{NC}^{+/+}\right)$were tested for guanylate cyclase activity in the presence and absence of $\mathrm{Ca}^{2+}$. The activity in membranes isolated in the absence of $\mathrm{Ca}^{2+}$ was about 66 pmol cyclic GMP 
$\min ^{-1}$ (mg protein $)^{-1}$ for the control and $\mathrm{NC} \delta^{+/-}$mice and the activity was not affected by the presence or absence of $\mathrm{Ca}^{2+}$ in the assay mixture. However, the activity in membranes isolated in the presence of $\mathrm{Ca}^{2+}$ was strongly dependent on the mice genotype and $\mathrm{Ca}^{2+}$ in the assay mixture. When assessed in the absence of $\mathrm{Ca}^{2+}$, the activity was $\sim 70$ pmol cyclic GMP $\min ^{-1}$ (mg protein $)^{-1}$ for the weight and $\mathrm{NC} \delta^{+/-}$mice but when assessed in the presence of $1 \mu \mathrm{M} \mathrm{Ca}^{2+}$ the activity was $223 \pm 20$ pmol cyclic GMP $\min ^{-1}$ (mg protein) ${ }^{-1}$ for the wild type mice and $135 \pm 10$ pmol cyclic GMP $\min ^{-1}(\mathrm{mg}$ protein $)^{-1}$ for the $\mathrm{NC}^{+/-}$mice. Thus, the $\mathrm{Ca}^{2+}$-dependent NC $\delta$-modulated ANF-RGC signaling pathway in the mice with one copy of $\mathrm{NC} \delta$ gene deleted $\left(\mathrm{NC} \delta^{+/-}\right)$is functionally half as active as in the wild type mice. To further authenticate that the lowering of the $\mathrm{Ca}^{2+}$-dependent cyclase activity in the adrenal gland membranes of $\mathrm{NC}^{+/-}$mice is the exclusive consequence of lower NC $\delta$ expression, $2 \mu \mathrm{M}$ exogenous NC $\delta$ was added to the $\mathrm{NC}^{+/+}$and $\mathrm{NC}^{+/-}$membranes (isolated in the presence of $\mathrm{Ca}^{2+}$ ) and the cyclase activity was determined in the presence of $1 \mu \mathrm{M} \mathrm{Ca}^{2+}$. The cyclase activity in the $\mathrm{NC}^{+/+}$adrenal membranes increased only minimally, from 220 to $279 \pm 21$ pmol cyclic GMP $\min ^{-1}$ (mg protein $)^{-1}$ but in the $\mathrm{NC} \delta^{+/-}$membranes, the increase was significantly larger, from 133 to $284 \pm 24$ (Duda et al., 2012b). Thus, the activity achieved was practically the same for both types of membranes. Hence, addition of exogenous NC $\delta$ to the $\mathrm{NC} \delta^{+/-}$adrenal gland membranes restores the guanylate cyclase activity and brings it to the level of activity in the $\mathrm{NC} \delta^{+/+}$ membranes. We rationalized that the slight activity increase in the $\mathrm{NC}^{+/+}$membranes observed upon addition of exogenous NC $\delta$ is caused by a partial loss of the native NC $\delta$ during the membrane preparation.

What is the function of this pathway in the adrenal gland? In general, the primary role of ANF-RGC in the adrenal gland is to offset the renin-angiotensin system and inhibit aldosterone synthesis, and by doing this, to lower blood pressure (Burnett etal., 1984; Aoki et al., 2000; Shi et al., 2001). Therefore, is the $\mathrm{Ca}^{2+}$-dependent ANF-RGC signal transduction machinery in the adrenal gland involved in aldosterone synthesis? Our ongoing studies indicate that indeed it is. The plasma aldosterone levels in the $\mathrm{NC}^{+/-}$mice are approximately $27 \%$ higher than in the plasma of the control $\left(\mathrm{NC}^{+/+}\right)$ mice. And the effect is exclusive for the aldosterone synthesizing glomerulosa cells, because corticosterone (synthesized in fasciculate cells) levels are unaffected by the absence of NC $\delta$ gene.

The increased plasma aldosterone level in the $\mathrm{NC}^{+/-}$mice correlates with the increase in blood pressure. Systolic blood pressure (measured by the non-invasive tail cuff method) was determined to be $92 \pm 6 \mathrm{~mm} \mathrm{Hg}$ for the wild type mice and $127 \pm 9 \mathrm{~mm} \mathrm{Hg}$ for the $\mathrm{NC} \delta^{+/-}$mice. Therefore, the conclusion of these studies was that the ANF-RGC- $\mathrm{Ca}^{2+}-\mathrm{NC} \delta$ transduction system is not only physically present but is of physiological significance at least in the adrenal gland.

In summary, this review has high-lighted studies which define the molecular and physiological mechanisms of the hormonal signal transduction of ANF-RGC. In addition, a new signal transduction mechanism and its present state of validation has been narrated. In this model $\mathrm{Ca}^{2+}$ is the additional signal of ANF-RGC. By entirely different mechanism, it regulates ANF-RGC catalytic activity and controls its physiological functions.

\section{FUTURE DIRECTIONS}

There are three venues through which, in these authors' understanding, the future research will progress. The first venue is centered on the basic research to decipher (1) how the ${ }^{669}{ }^{\text {WTAPELL }}{ }^{675}$ motif "communicates" with the catalytic domain of ANF-RGC and signals its activation and (2) the mechanism of NC $\delta-\mathrm{Ca}^{2+}$ signaling of ANF-RGC activity. The second venue relates to the physiology of both ANF-RGC signaling pathways (1) establishing whether the $\mathrm{Ca}^{2+}$ signaling mechanism is operative in other tissues in addition to the adrenal gland and (2) to determine the interrelationship of the hormonal and $\mathrm{Ca}^{2+}$ pathways. Finally, after deciphering the molecular and physiological details of the two signaling pathway the third venue will be translational, to design a molecule that can target directly the catalytic domain and bring ANF-RGC to its full activity and prevent the pandemic of hypertension, myocardial hypertrophy and obesity. The last objective is the most far-reaching, but hopefully can be achieved after the first two goals are accomplished.

\section{ACKNOWLEDGMENTS}

The numerous NIH and NSF support (Rameshwar K. Sharma) is acknowledged for the pioneering studies on ANF-RGC signal transduction field and the HL084584 and S82701 support (Teresa Duda) is acknowledged for the development of the ${ }^{669}$ WTAPELL $^{675}$ and $\mathrm{Ca}^{2+}$ signaling mechanisms.

\section{REFERENCES}

Aoki, H., Richmond, M., Izumo, S., and Sadoshima, J. (2000). Specific role of the extracellular signal-regulated kinase pathway in angiotensin II-induced cardiac hypertrophy in vitro. Biochem. J. 347, 275-284. doi: 10.1042/0264-6021:3470275

Bratová, I., Otyepka, M., Křiž, Z., and Koča, J. (2005). The mechanism of inhibition of the cyclin-dependent kinase- 2 as revealed by the molecular dynamics study on the complex CDK2 with the peptide substrate HHASPRK. Protein Sci. 14, 445-451. doi: 10.1110/ps.04959705

Brenner, B. M., Ballermann, B. J., Gunning, M. E., and Zeidel, M. L. (1990). Diverse biological actions of atrial natriuretic peptide. Physiol. Rev. 7, 665-669.

Burczynska, B., Duda, T., and Sharma, R. K. (2007). ATP signaling site in the ARM domain of atrial natriuretic factor receptor guanylate cyclase. Mol. Cell. Biochem. 301, 193-207. doi: 10.1007/s11010-006-9400-7

Burnett, J. C. Jr., Granger, J. P., and Opgenorth, T. J. (1984). Effect of synthetic atrial natriuretic factor on renal function and rennin release. Am. J. Physiol. 247, F863-F866.

Chang, C. H., Kohse, K. P., Chang, B., Hirata, M., Jiang, B., Douglas, J. E., et al. (1990). Characterization of ATP-stimulated guanylate cyclase activation in rat lung membranes. Biochim. Biophys. Acta 1052, 159-165. doi: 10.1016/01674889(90)90071-K

Chang, M. S., Lowe, D. G., Lewis, M., Hellmiss, R., Chen, E., and Goeddel, D. V. (1989). Differential activation by atrial and brain natriuretic peptides of two different receptor guanylate cyclases. Nature 341, 68-72. doi: 10.1038/341068a0

Chao, Y.-C., Cheng, C.-J., Hsieh, H.-T., Lin, C.-C., Chen, C.-C., and Yang, R.-B. (2010). Guanylate cyclase-G, expressed in the Grueneberg ganglion olfactory subsystem, is activated by bicarbonate. Biochem. J. 432, 267-273. doi: 10.1042/BJ20100617

Chinkers, M., and Garbers, D. L. (1989). The protein kinase domain of the ANP receptor is required for signaling. Science 245, 1392-1394. doi: 10.1126/science. 2571188 
Chinkers, M., Garbers, D. L., Chang, M. S., Lowe, D. G., Chin, H. M., Goeddel, D. V., et al. (1989). A membrane form of guanylate cyclase is an atrial natriuretic peptide receptor. Nature 338, 78-83. doi: 10.1038/338078a0

Chinkers, M., Singh, S., and Garbers, D. L. (1991). Adenine nucleotides are required for activation of rat atrial natriuretic peptide receptor/guanylyl cyclase expressed in a baculovirus system. J. Biol. Chem. 266, 4088-4093.

Cole, F. E., Rondon, I., Iwata, T., Hardee, E., and Frohlich, E. D. (1989) Effect of ATP and amiloride on ANF binding and stimulation of cyclic GMP accumulation in rat glomerular membranes. Life Sci. 45, 477-484. doi: 10.1016/0024-3205(89)90097-0

Coussen, F., and Mulle, C. (2006). Kainate receptor-interacting proteins and membrane trafficking. Biochem. Soc. Trans. 34, 927-930. doi: 10.1042/BST0340927

Das, S., Au, E., Krazit, S. T., and Pandey, K. N. (2010). Targeted disruption of guanylyl cyclase-A/natriuretic peptide receptor-A gene provokes renal fibrosis and remodeling in null mutant mice: role of proinflammatory cytokines. Endocrinology 151 5841-5850. doi: 10.1210/en.2010-0655

de Bold, A. J. (1985). Atrial natriuretic factor: a hormone produced by the heart Science 230, 767-770. doi: 10.1126/science.2932797

de Sauvage, F. J., Camerato, T. R., and Goeddel, D. V. (1991). Primary structure and functional expression of the human receptor for Escherichia coli heat-stable enterotoxin. J. Biol. Chem. 266, 17912-17918.

Detwiler, P. (2000). Open the loop: dissecting feedback regulation of a second messenger transduction cascade. Neuron 36, 3-4. doi: 10.1016/S08966273(02)00940-6

Dizhoor, A. M., Olshevskaya, E. V., Henzel, W. J., Wong, S. C., Stults, J. T., Ankoudinova, I., et al. (1995). Cloning, sequencing, and expression of a $24-\mathrm{kDa}$ $\mathrm{Ca} 2+-$ binding protein activating photoreceptor guanylyl cyclase. J. Biol. Chem. 270, 25200-25206. doi: 10.1074/jbc.270.42.25200

Dubois, S. K., Kishimoto, I., Lillis, T. O., and Garbers, D. L. (2000). A genetic model defines the importance of the atrial natriuretic peptide receptor (guanylyl cyclase-A) in the regulation of kidney function. Proc. Natl. Acad. Sci. U.S.A. 97, 4369-4373. doi: 10.1073/pnas.97.8.4369

Duda, T., Bharill, S., Wojtas, I., Yadav, P., Gryczynski, I., Gryczynski, Z., et al. (2009). Atrial natriuretic factor receptor guanylate cyclase signaling: new ATP-regulated transduction motif. Mol. Cell. Biochem. 324, 39-53. doi: 10.1007/s11010-008 9983-2

Duda, T., Fik-Rymarkiewicz, E., Venkataraman, V., Krishnan, A., and Sharma, R. K. (2004). Calcium-modulated ciliary membrane guanylate cyclase transduction machinery: constitution and operational principles. Mol. Cell. Biochem. 267, 107-122. doi: 10.1023/B:MCBI.0000049372. 33965.4f

Duda, T., Goraczniak, R. M., and Sharma, R. K. (1991). Site-directed mutational analysis of a membrane guanylate cyclase cDNA reveals the atrial natriuretic factor signaling site. Proc. Natl. Acad. Sci. U.S.A. 88, 7882-7886. doi $10.1073 /$ pnas.88.17.7882

Duda, T., Goraczniak, R. M., and Sharma, R. K. (1993a). The glycine residue of ATP regulatory module in receptor guanylate cyclases that is essential in natriuretic factor signaling. FEBS Lett. 335, 309-314. doi: 10.1016/0014-5793(93)80408-M

Duda, T., Goraczniak, R. M., Sitaramayya, A., and Sharma, R. K. (1993b). Cloning and expression of an ATP-regulated human retina C-type natriuretic factor receptor guanylate cyclase. Biochemistry 32, 1391-1395. doi: 10.1021/bi00057a001

Duda, T., Goraczniak, R. M., and Sharma, R. K. (1996a). Molecular characterization of S100A1-S100B protein in retina and its activation mechanism of bovine photoreceptor guanylate cyclase. Biochemistry 35, 6263-6266. doi 10.1021/bi960007m

Duda, T., Goraczniak, R., Surgucheva, I., Rudnicka-Nawrot, M., Gorczyca, W. A., Palczewski, K., et al. (1996b). Calcium modulation of bovine photoreceptor guanylate cyclase. Biochemistry 35, 8478-8482. doi: 10.1021/bi960752z

Duda, T., Jankowska, A., Venkataraman, V., Nagele, R. G., and Sharma, R. K. (2001a). A novel calcium-regulated membrane guanylate cyclase transduction system in the olfactory neuroepithelium. Biochemistry 40, 12067-12077. doi: 10.1021/bi0108406

Duda, T., Yadav, P., Jankowska, A., Venkataraman, V., and Sharma, R. K. (2001b) Three dimensional atomic model and experimental validation for the ATPRegulated Module (ARM) of the atrial natriuretic factor receptor guanylate cyclase. Mol. Cell. Biochem. 217, 165-172. doi: 10.1023/A:1007236917061

Duda, T., Krishnan, R., and Sharma, R. K. (2006). GCAP1: antithetical calcium sensor of ROS-GC transduction machinery. Calcium Bind. Proteins 1, 102-107.
Duda, T., Pertzev, A., Koch, K. W., and Sharma, R. K. (2012a). Antithetical modes of and the Ca2 + sensors targeting in ANF-RGC and ROS-GC1 membrane guanylate cyclases. Front. Mol. Neurosci. 5:44. doi: 10.3389/fnmol.2012. 00044

Duda, T., Pertzev, A., and Sharma, R. K. (2012b). Ca(2+) modulation of ANF-RGC: new signaling paradigm interlocked with blood pressure regulation. Biochemistry 51, 9394-9405. doi: 10.1021/bi301176c

Duda, T., Pertzev, A., and Sharma, R. K. (2013). The ANF-RGC gene motif (669)WTAPELL(675) is vital for blood pressure regulation: Biochemical mechanism. Biochemistry 52, 2337-2334. doi: 10.1021/bi400175d

Duda, T., and Sharma, R. K. (1995). ATP bimodal switch that regulates the ligand binding and signal transduction activities of the atrial natriuretic factor receptor guanylate cyclase. Biochem. Biophys. Res. Commun. 209, 286-292. doi: 10.1006/bbrc.1995.1501

Duda, T., and Sharma, R. K. (2005). Two membrane juxtaposed signaling modules in ANF-RGC are interlocked. Biochem. Biophys. Res. Commun. 332, 149-156. doi: 10.1016/j.bbrc.2005.04.102

Duda, T., and Sharma, R. K. (2008). ONE-GC membrane guanylate cyclase, a trimodal odorant signal transducer. Biochem. Biophys. Res. Commun. 367, 440444. doi: 10.1016/j.bbrc.2007.12.153

Duda., T., and Sharma, R. K. (2009). Ca2+-modulated ONE-GC odorant signal transduction. FEBS Lett. 583, 1327-1330. doi: 10.1016/j.febslet.2009.03.036

Duda, T., Venkataraman, V., Ravichandran, S., and Sharma, R. K. (2005). ATPregulated module (ARM) of the atrial natriuretic factor receptor guanylate cyclase. Peptides 26, 969-984. doi: 10.1016/j.peptides.2004.08.032

Duda, T., Yadav, P., and Sharma, R. K. (2011). Allosteric modification, the primary ATP activation mechanism of atrial natriuretic factor receptor guanylate cyclase. Biochemistry 50, 1213-1212. doi: 10.1021/bi1018978

Ellis, K. L., Newton-Cheh, C., Wang, T. J., Frampton, C. M., Doughty, R. N., Whalley, G. A., et al. (2011). Association of genetic variation in the natriuretic peptide system with cardiovascular outcomes. J. Mol. Cell. Cardiol. 50, 695-701. doi: 10.1016/j.yjmcc.2011.01.010

Ellmers, L. J., Scott, N. J., Piuhola, J., Maeda, N., Smithies, O., Frampton, C. M., et al. (2007). Npr1-regulated gene pathways contributing to cardiac hypertrophy and fibrosis. J. Mol. Endocrinol. 38, 245-257. doi: 10.1677/jme.1.02138

Foster, D. C., and Garbers, D. L. (1998). Dual role for adenine nucleotides in the regulation of the atrial natriuretic peptide receptor, guanylyl cyclase-A. J. Biol. Chem. 273, 16311-16318. doi: 10.1074/jbc.273.26.16311

Fulle, H. J., Vassar, R., Foster, D. C., Yang, R. B., Axel, R., and Garbers, D. L. (1995). A receptor guanylyl cyclase expressed specifically in olfactory sensory neurons. Proc. Natl. Acad. Sci. U.S.A. 92, 3571-3575. doi: 10.1073/pnas.92.8.3571

Goraczniak, R. M., Duda, T., and Sharma, R. K. (1992). A structural motif that defines the ATP-regulatory module of guanylate cyclase in atrial natriuretic factor signalling. Biochem. J. 282, 533-537.

Goraczniak, R. M., Duda, T., and Sharma, R. K. (1998). Calcium modulated signaling site in type 2 rod outer segment membrane guanylate cyclase (ROS-GC2). Biochem. Biophys. Res. Commun. 245, 447-453. doi: 10.1006/bbrc.1998.8455

Goraczniak, R. M., Duda, T., Sitaramayya, A., and Sharma, R. K. (1994). Structural and functional characterization of the rod outer segment membrane guanylate cyclase. Biochem. J. 302, 455-461.

Hamra, F. K., Forte, L. R., Eber, S. L., Pidhorodeckyj, N. V., Krause, W. J., Freeman, R. H., et al. (1993). Uroguanylin: structure and activity of a second endogenous peptide that stimulates intestinal guanylate cyclase. Proc. Natl. Acad. Sci. U.S.A. 90, 10464-10468. doi: 10.1073/pnas.90.22.10464

Hanks, S. K., Quinn, A. M., and Hunter, T. (1988). The protein kinase family: conserved features and deduced phylogeny of the catalytic domains. Science 241, 42-52. doi: 10.1126/science.3291115

He, X., Nishio, K., and Misono, K. S. (1995). High-yield affinity alkylation of the atrial natriuretic factor receptor binding site. Bioconjug. Chem. 6, 541-548. doi: 10.1021/bc00035a007

Holtwick, R., van Eickels, M., Skryabin, B. V., Baba, H. A., Bubikat, A., Begrow, F., et al. (2003). Pressure independent cardiac hypertrophy in mice with cardiomyocyte-restricted inactivation of the atrial natriuretic peptide receptor guanyly cyclase-A. J. Clin. Invest. 111, 1399-1407. doi: 10.1172/JCI17061

Huo, X., Abe, T., and Misono, K. S. (1999). Ligand binding-dependent limited proteolysis of the atrial natriuretic peptide receptor: juxtamembrane hinge structure essential for transmembrane signal transduction. Biochemistry 38, 16941-16951. doi: 10.1021/bi9919448 
Iino, S., Kobayashi, S., Okazaki, K., and Hidaka, H. (1995). Immunohistochemical localization of neurocalcin in the rat inner ear. Brain Res. 680, 128-134. doi: 10.1016/0006-8993(95)00253-M

Ivings, L., Pennington, S. R., Jenkins, R., Weiss, J. L., and Burgoyne, R. D. (2002). Identification of $\mathrm{Ca} 2+$-dependent binding partners for the neuronal calcium sensor protein neurocalcin delta: interaction with actin, clathrin and tubulin. Biochem. J. 363, 599-608. doi: 10.1042/0264-6021:3630599

Katholi, R. E., and Couri, D. M. (2011). Left ventricular hypertrophy: major risk factor in patients with hypertension: update and practical clinical applications. Int. J. Hypertens. 2011, 495349. doi: 10.4061/2011/495349

Khare, S., Wilson, D., Wali, R. K., Tien, X. Y., Bissonnette, M., Niedziela, S. M., et al. (1994). Guanylin activates rat colonic particulate guanylate cyclase. Biochem. Biophys. Res. Commun. 203, 1432-1437. doi: 10.1006/bbrc.1994.2345

Kishimoto, I., Rossi, K., and Garbers, D. L. (2001). A genetic model provides evidence that the receptor for atrial natriuretic peptide (guanylyl cyclase-A) inhibits cardiac ventricular myocyte hypertrophy. Proc. Natl. Acad. Sci. U.S.A. 98, 2703-2706. doi: 10.1073/pnas.051625598

Knowles, J. W., Esposito, G., Mao, L., Hagaman, J. R., Fox, J. E., Smithies, O., et al. (2001). Pressure independent enhancement of cardiac hypertrophy in natriuretic peptide receptor A-deficient mice. J. Clin. Invest. 107, 975-984. doi: 10.1172/JCI11273

Koch, K.-W. (1991). Purification and identification of photoreceptor guanylate cyclase. J. Biol. Chem. 266, 8634-8637.

Koch, K.-W., Duda, T., and Sharma, R. K. (2010). Ca2+-modulated vision-linked ROS-GC guanylate cyclase transduction machinery. Mol. Cell. Biochem. 334, 105-115. doi: 10.1007/s11010-009-0330-z

Kuhn, M., Ng, C. K., Su, Y. H., Kilić, A., Mitko, D., Bien-Ly, N., et al. (2004). Identification of an orphan guanylate cyclase receptor selectively expressed in mouse testis. Biochem. J. 379, 385-393. doi: 10.1042/BJ20031624

Kumar, V. D., Vijay-Kumar, S., Krishnan, A., Duda, T., and Sharma, R. K. (1999). A second calcium regulator of rod outer segment membrane guanylate cyclase, ROS-GC1: neurocalcin. Biochemistry 38, 12614-12620. doi: 10.1021/bi990851n

Krishnan, A., Venkataraman, V., Fik-Rymarkiewicz, E., Duda, T., and Sharma, R. K. (2004). Structural, biochemical, and functional characterization of the calcium sensor neurocalcin delta in the inner retinal neurons and its linkage with the rod outer segment membrane guanylate cyclase transduction system. Biochemistry 43, 2708-2723. doi: 10.1021/bi035631v

Kuno, T., Andresen, J. W., Kamisaki, Y., Waldman, S. A., Chang, L. Y., Saheki, S., et al. (1986). Co-purification of an atrial natriuretic factor receptor and particulate guanylate cyclase from rat lung. J. Biol. Chem. 261, 5817-5823.

Kurose, H., Inagami, T., and Ui, M. (1987). Participation of adenosine $5^{\prime}$ triphosphate in the activation of membrane-bound guanylate cyclase by the atrial natriuretic factor. FEBS Lett. 219, 375-379. doi: 10.1016/0014-5793(87)80256-9

Labrecque, J., Deschênes, J., McNicoll, N., and De Léan, A. (2001). Agonistic induction of a covalent dimer in a mutant of natriuretic peptide receptor-A documents a juxtamembrane interaction that accompanies receptor activation. J. Biol. Chem. 276, 8064-8072. doi: 10.1074/jbc.M005550200

Labrecque, J., Mc Nicoll, N., Marquis, M., and De Lean, A. (1999). A disulfidebridged mutant of natriuretic peptide receptor-A displays constitutive activity. Role of receptor dimerization in signal transduction. J. Biol. Chem. 274, 97529759. doi: 10.1074/jbc.274.14.9752

Ladant, D. (1995). Calcium and membrane binding properties of bovine neurocalcin delta expressed in Escherichia coli. J. Biol. Chem. 270, 3179-3185.

Larose, L., McNicoll, N., Ong, H., and De Léan, A. (1991). Allosteric modulation by ATP of the bovine adrenal natriuretic factor R1 receptor functions. Biochemistry 30, 8990-8995. doi: 10.1021/bi00101a012

Leinders-Zufall, T., Cockerham, R. E., Michalakis, S., Biel, M., Garbers, D. L., Reed, R. R., et al. (2007). Contribution of the receptor guanylyl cyclase GC-D to chemosensory function in the olfactory epithelium. Proc. Natl. Acad. Sci. U.S.A. 104, 14507-14512. doi: 10.1073/pnas.0704965104

Liu, Y., Ruoho, A. E., Rao, V. D., and Hurley, J. H. (1997). Catalytic mechanism of the adenylyl and guanylyl cyclases: modeling and mutational analysis. Proc. Natl. Acad. Sci. U.S.A. 94, 13414-13419. doi: 10.1073/pnas.94.25.13414

Lowe, D. G., Chang, M. S., Hellmiss, R., Chen, E., Singh, S., Garbers, D. L., et al. (1989). Human atrial natriuretic peptide receptor defines a new paradigm for second messenger signal transduction. EMBO J. 8, 1377-13784.

Lowe, D. G., Dizhoor, A. M., Liu, K., Gu, Q., Spencer, M., Laura, R., et al. (1995). Cloning and expression of a second photoreceptor-specific membrane retina guanylyl cyclase (RetGC), RetGC-2. Proc. Natl. Acad. Sci. U.S.A. 92, 5535-5539. doi: 10.1073/pnas.92.12.5535

Maack, T. (1996). Role of atrial natriuretic factor in volume control. Kidney Int. 49, 1732-1737. doi: 10.1038/ki.1996.257

Mamasuew, K., Breer, H., and Fleischer, J. (2008). Gruenberg ganglion neurons respond to cool ambient temperatures. Eur. J. Neurosci. 28, 1775-1785. doi: 10.1111/j.1460-9568.2008.06465.x

Marala, R., Duda, T., Goraczniak, R. M., and Sharma, R. K. (1992). Genetically tailored atrial natriuretic factor-dependent guanylate cyclase. Immunological and functional identity with $180 \mathrm{kDa}$ membrane guanylate cyclase and ATP signaling site. FEBS Lett. 296, 254-258. doi: 10.1016/0014-5793(92)80298-U

Marala, R. B., Sitaramayya, A., and Sharma, R. K. (1991). Dual regulation of atrial natriuretic factor-dependent guanylate cyclase activity by ATP. FEBS Lett. 281, 73-76. doi: 10.1016/0014-5793(91)80361-6

Margulis, A., Pozdnyakov, N., and Sitaramayya, A. (1996). Activation of bovine photoreceptor guanylate cyclase by $\mathrm{S} 100$ proteins. Biochem. Biophys. Res. Commun. 218, 243-247. doi: 10.1006/bbrc.1996.0043

McNicoll, N., Escher, E., Wilkes, B. C., Schiller, P. W., Ong, H., and De Léan, A. (1992). Highly efficient photoaffinity labeling of the hormone binding domain of atrial natriuretic factor receptor. Biochemistry 31, 4487-4493. doi: 10.1021/bi00133a015

McNicoll, N., Gagnon, J., Rondeau, J. J., Ong, H., and De Léan, A. (1996). Localization by photoaffinity labeling of natriuretic peptide receptor-A binding domain. Biochemistry 35, 12950-12956. doi: 10.1021/bi960818q

Meloche, S., McNicoll, N., Liu, B., Ong, H., and De Lean, A. (1988). Atrial natriuretic factor R1 receptor from bovine adrenal zona glomerulosa: purification, characterization, and modulation by amiloride. Biochemistry $27,8151-8158$. doi: 10.1021/bi00421a025

Miao, Z. H., Song, D. L., Douglas, J. G., and Chang, C. H. (1995). Mutational inactivation of the catalytic domain of guanylate cyclase-A receptor. Hypertension 25, 694-698. doi: 10.1161/01.HYP.25.4.694

Misono, K. S. (2002). Natriuretic peptide receptor: structure and signaling. Mol. Cell. Biochem. 230, 49-60. doi: 10.1023/A:1014257621362

Misono, K. S., Ogawa, H., Qiu, Y., and Ogata, C. M. (2005). Structural studies of the natriuretic peptide receptor: a novel hormone-induced rotation mechanism for transmembrane signal transduction. Peptides 26, 957-968. doi: 10.1016/j.peptides.2004.12.021

Misono, K. S., Philo, J. S., Arakawa, T., Ogata, C. M., Qiu, Y., Ogawa, H., et al. (2011). Structure, signaling mechanism and regulation of the natriuretic peptide receptor guanylate cyclase. FEBS J. 278, 1818-1829. doi: 10.1111/j.1742-4658.2011.08083.x Miyagi, M., and Misono, K. S. (2000). Disulfide bond structure of the atrial natriuretic peptide receptor extracellular domain: conserved disulfide bonds among guanylate cyclase-coupled receptors. Biochim. Biophys. Acta 1478, 30-38. doi: 10.1016/S0167-4838(00)00002-9

Nakano, A., Terasawa, M., Watanabe, M., Okazaki, K., Inoue, S., Kato, M., et al. (1993). Distinct regional localization of neurocalcin, a Ca2+-binding protein, in the bovine adrenal gland. J. Endocrinol. 138, 283-290. doi: 10.1677/joe.0.1380283

Ogawa, H., Qiu, Y., Huang, L., Tam-Chang, S. W., Young, H. S., and Misono, K. S. (2009). Structure of the atrial natriuretic peptide receptor extracellular domain in the unbound and hormone-bound states by single-particle electron microscopy. FEBS J. 276, 1347-1355. doi: 10.1111/j.1742-4658.2009. 06870.x

Ogawa, H., Qiu, Y., Ogata, C. M., and Misono, K. S. (2004). Crystal structure of hormone-bound atrial natriuretic peptide receptor extracellular domain: rotation mechanism for transmembrane signal transduction. J. Biol. Chem. 279, 2862528631. doi: 10.1074/jbc.M313222200

Ogawa, H., Zhang, X., Qiu, Y., Ogata, C. M., and Misono, K. S. (2003) Crystallization and preliminary X-ray analysis of the atrial natriuretic peptide (ANP) receptor extracellular domain complex with ANP: use of ammonium sulfate as the cryosalt. Acta Crystallogr. D Biol. Crystallogr. 59, 1831-1833. doi: 10.1107/S0907444903016445

Okazaki, K., Obata, N. H., Inoue, S., and Hidaka, H. (1995). S100 beta is a target protein of neurocalcin delta, an abundant isoform in glial cells. Biochem. J. 306, 551-555.

Oliver, P. M., Fox, J. E., Kim, R., Rockman, H. A., Kim, H. S., Reddick, R. L., et al. (1997). Hypertension, cardiac hypertrophy, and sudden death in mice lacking natriuretic peptide receptor A. Proc. Natl. Acad. Sci. U.S.A. 94, 14730-14735. doi: $10.1073 /$ pnas. 94.26 .14730 
Olson, L. J., Ho, B., Cashdollar, L. W., and Drewett, J. G. (1998). Functionally active catalytic domain is essential of guanylyl cyclase-linked receptor mediated inhibition of human aldosterone synthesis. Mol. Pharmacol. 54, 761-769.

Palczewski, K., Subbaraya, I., Gorczyca, W. A., Helekar, B. S., Ruiz, C. C., Ohguro, H., etal. (1994). Molecular cloning and characterization of retinal photoreceptor guanylyl cyclase-activating protein. Neuron 13, 395-404. doi: 10.1016/0896-6273(94)90355-7

Pandey, K. N. (2011). Guanylyl cyclase/atrial natriuretic peptide receptor-A: role in the pathophysiology of cardiovascular regulation. Can. J. Physiol. Pharmacol. 89, 557-573. doi: 10.1139/y11-054

Pandey, K. N., and Singh, S. (1990). Molecular cloning and expression of murine guanylate cyclase/atrial natriuretic factor receptor cDNA. J. Biol. Chem. 265, 12342-12348.

Parat, M., Blanchet, J., and De Léan, A. (2010). Role of juxtamembrane and transmembrane domains in the mechanism of natriuretic peptide receptor A activation. Biochemistry 49, 4601-4610. doi: 10.1021/bi901711w

Paul, A. K. (1986). Particulate Guanylate Cyclase from Adrenocortical Carcinoma 494. Purification, Biochemical and Immunological Characterization. Ph.D. thesis University of Tennessee.

Paul, A. K., Marala, R. B., Jaiswal, R. K., and Sharma, R. K. (1987). Coexistence of guanylate cyclase and atrial natriuretic factor receptor in a $180-\mathrm{kD}$ protein. Science 235, 1224-1226. doi: 10.1126/science. 2881352

Pertzev, A., Duda, T., and Sharma, R. K. (2010). Ca2+ sensor GCAP1: a constitutive element of the ONE-GC-modulated odorant signal transduction pathway. Biochemistry 49, 7303-7313. doi: 10.1021/bi101001v

Potter, L. R., and Hunter, T. (1998a). Phosphorylation of the kinase homology domain is essential for activation of the A-type natriuretic peptide receptor. Mol Cell. Biol. 18, 2164-2172.

Potter, L. R., and Hunter, T. (1998b). Identification and characterization of the major phosphorylation sites of the B-type natriuretic peptide receptor. J. Biol. Chem. 273, 15533-15539. doi: 10.1074/jbc.273.25. 15533

Potter, L. R., and Hunter, T. (1999a). Identification and characterization of the phosphorylation sites of the guanylyl cyclase-linked natriuretic peptide receptors A and B. Methods 19, 506-520. doi: 10.1006/meth. 1999.0893

Potter, L. R., and Hunter, T. (1999b). A constitutively "phosphorylated" guanylyl cyclase-linked atrial natriuretic peptide receptor mutant is resistant to desensitization. Mol. Biol. Cell 10, 1811-1820. doi: 10.1091/mbc.10.6.1811

Pozdnyakov, N., Yoshida, A., Cooper, N. G., Margulis, A., Duda, T., Sharma, R. K., et al. (1995). A novel calcium-dependent activator of retinal rod outer segment membrane guanylate cyclase. Biochemistry 34, 14279-14283. doi: 10.1021/bi00044a002

Pugh, E. N. Jr., Duda, T., Sitaramayya, A., and Sharma, R. K. (1997). Photoreceptor guanylate cyclases: a review. Biosci. Rep. 17, 429-473. doi 10.1023/A:1027365520442

Rebello, M. R., Aktas, A., and Medler, K. F. (2011). Expression of calcium binding proteins in mouse type II taste cells. J. Histochem. Cytochem. 59, 530-539. doi: $10.1369 / 0022155411402352$

Rondeau, J. J., McNicoll, N., Gagnon, J., Bouchard, N., Ong, H., and De Léan, A. (1995). Stoichiometry of the atrial natriuretic factor-R1 receptor complex in the bovine zona glomerulosa. Biochemistry 34, 2130-2136. doi: 10.1021/bi00007a005

Schulz, S., Green, C. K., Yuen, P. S., and Garbers, D. L. (1990). Guanylyl cyclase is a heat-stable enterotoxin receptor. Cell 63, 941-948. doi: 10.1016/00928674(90)90497-3

Schulz, S., Singh, S., Bellet, R. A., Singh, G., Tubb, D. J., Chin, H., et al. (1989) The primary structure of a plasma membrane guanylate cyclase demonstrates diversity within this new receptor family. Cell 58, 1155-1162. doi: 10.1016/00928674(89)90513-8

Schulz, S., Wedel, B. J., Matthews, A., and Garbers, D. L. (1998). The cloning and expression of a new guanylyl cyclase orphan receptor. J. Biol. Chem. 273, 1032-1037. doi: 10.1074/jbc.273.2.1032

Sharma, R. K. (2002). Evolution of the membrane guanylate cyclase transduction system. Mol. Cell. Biochem. 230, 3-30. doi: 10.1023/A:1014280410459

Sharma, R. K. (2010). Membrane guanylate cyclase is a beautiful signal transduction machine: overview. Mol. Cell. Biochem. 334, 3-36. doi: 10.1007/s11010-0090336-6
Sharma, R. K., and Duda, T. (2010). Odorant-linked ROS-GC subfamily membrane guanylate cyclase transduction system. Mol. Cell. Biochem. 334, 181-189. doi: 10.1007/s11010-009-0333-9

Sharma, R. K., Jaiswal, R. K., and Duda, T. (1988a). "Second messenger role of cyclic GMP in atrial natriuretic factor receptor mediated signal transduction: $180 \mathrm{kDa}$ membrane guanylate cyclase, its coupling with atrial natriuretic factor receptor and its regulation by protein kinase C," in Biological and Molecular Aspects of Atrial Factors, ed. Needleman (New york: Alan R. Liss, Inc.), 77-96.

Sharma, R. K., Marala, R. B., and Paul, A. K. (1988b). "Mediatory role of cyclic GMP in receptor-mediated signal transduction: membrane guanylate cyclase and its coupling with atrial natriuretic factor receptor," in American Society of Hypertension Symposium Series, Advances in Peptide Research, Vol 2, eds B. M. Brenner and J. H. Laragh (New York: Raven Press), 61-77.

Sharma, R. K., Marala, R. B., and Duda, T. (1989). Purification and characterization of the $180-\mathrm{kDa}$ membrane guanylate cyclase containing atrial natriuretic factor receptor from rat adrenal gland and its regulation by protein kinase C. Steroids 53, 437-460. doi: 10.1016/0039-128X(89)90024-X

Sharma, R. K., Yadav, P., and Duda, T. (2001). Allosteric regulatory step and configuration of the ATP-binding pocket in atrial natriuretic factor receptor guanylate cyclase transduction mechanism. Can. J. Physiol. Pharmacol. 79, 682-691. doi: 10.1139/y01-033

Shi, S.-J, Nguyen, H. T., Sharma, G. D., Navar, G., and Pandey, K. N. (2001). Genetic disruption of atrial natriuretic peptide receptor-A alters rennin and angiotensinII levels. Am. J. Physiol. Renal Physiol. 281, F665-F673.

Shyjan, A. W., de Sauvage, F. J., Gillett, N. A., Goeddel, D. V., and Lowe, D. G. (1992). Molecular cloning of a retina-specific membrane guanylyl cyclase. Neuron 9, 727-737. doi: 10.1016/0896-6273(92)90035-C

Singh, S., Singh, G., Heim, J. M., and Gerzer, R. (1991). Isolation and expression of a guanylate cyclase-coupled heat stable enterotoxin receptor cDNA from a human colonic cell line. Biochem. Biophys. Res. Commun. 179, 1455-1463. doi: 10.1016/0006-291X(91)91736-V

Takayanagi, R., Inagami, T., Snajdar, R. M., Imada, T., Tamura, M., and Misono, K. S. (1987). Two distinct forms of receptors for atrial natriuretic factor in bovine adrenocortical cells. Purification, ligand binding, and peptide mapping. J. Biol. Chem. 262, 12104-12113.

Thompson, D. K., and Garbers, D. L. (1995). Dominant negative mutations of the guanylyl cyclase-A receptor. Extracellular domain deletion and catalytic domain point mutations. J. Biol. Chem. 270, 425-430. doi: 10.1074/jbc. 270.1 .425

Thorpe, D. S., and Morkin, E. (1990). The carboxyl region contains the catalytic domain of the membrane form of guanylate cyclase. J. Biol. Chem. 265, 1471714720 .

Thorpe, D. S., Niu, S., and Morkin, E. (1996). The guanylyl cyclase core of an atrial natriuretic peptide receptor: enzymatic properties and basis for cooperativity. Biochem. Biophys. Res. Commun. 218, 670-673. doi: 10.1006/bbrc.1996.0120

Tremblay, J., Huot, C., Koch, C., and Potier, M. (1991). Characterization of the functional domains of the natriuretic peptide receptor/guanylate cyclase by radiation inactivation. J. Biol. Chem. 266, 8171-8175.

Tucker, C. L., Hurley, J. H., Miller, T. R., and Hurley, J. B. (1998). Two amino acid substitutions convert a guanylyl cyclase, RetGC-1, into an adenylyl cyclase. Proc. Natl. Acad. Sci. U.S.A. 95, 5993-5997. doi: 10.1073/pnas.95.11.5993

Venkataraman, V., Duda, T., Ravichandran, S., and Sharma, R. K. (2008). Neurocalcin delta modulation of ROS-GC1, a new model of Ca2+ signaling. Biochemistry 47, 6590-6601. doi: 10.1021/bi800394s

Vijay-Kumar, S., and Kumar, V. D. (1999). Crystal structure of recombinant bovine neurocalcin. Nat. Struct. Biol. 6, 80-88. doi: 10.1038/4956

Wadei, H. M., and Textor, S. C. (2012). The role of the kidney in regulating arterial blood pressure. Nat. Rev. Nephrol. 8, 602-609. doi: 10.1038/nrneph.2012.191

Wedel, B. J., Foster, D. C., Miller, D. E., and Garbers, D. L. (1997). A mutation of the atrial natriuretic peptide (guanylyl cyclase-A) receptor results in a constitutively hyperactive enzyme. Proc. Natl. Acad. Sci. U.S.A. 94, 459-462. doi: 10.1073/pnas.94.2.459

Wedel, B. J., and Garbers, D. L. (1997). New insights on the functions of the guanylyl cyclase receptors. FEBS Lett. 410, 29-33. doi: 10.1016/S0014-5793(97)00358-X

Wen, X. H., Duda, T., Pertzev, A., Venkataraman, V., Makino, C. L., and Sharma, R. K. (2012). S100B serves as a Ca2+ sensor for ROS-GC1 guanylate cyclase in cones but not in rods of the murine retina. Cell. Physiol. Biochem. 29, 417-430. doi: $10.1159 / 000338496$ 
Wierenga, R. K., and Hol, W. G. (1983). Predicted nucleotide-binding properties of p21 protein and its cancer-associated variant. Nature 302, 842-844. doi: $10.1038 / 302842 \mathrm{a} 0$

Wilson, E. M., and Chinkers, M. (1995). Identification of sequences mediating guanylyl cyclase dimerization. Biochemistry 34, 4696-4701. doi: 10.1021/bi00014a025

Wong, S. K., Ma, C. P., Foster, D. C., Chen, A. Y., and Garbers, D. L. (1995). The guanylyl cyclase-A receptor transduces an atrial natriuretic peptide/ATP activation signal in the absence of other proteins. J. Biol. Chem. 270, 30818-30822. doi: 10.1074/jbc.270.51.30818

Yang, R. B., Foster, D. C., and Garbers, D. L., and Fulle, H. J. (1995). Two membrane forms of guanylyl cyclase found in the eye. Proc. Natl. Acad. Sci. U.S.A. 92, 602-606. doi: 10.1073/pnas.92.2.602

Zhao, D., Vellaichamy, E., Somanna, N. K., and Pandey, K. N. (2007). Guanylyl cyclase/natriuretic peptide receptor-A gene disruption causes increased adrenal angiotensin II and aldosterone levels. Am. J. Physiol. Renal Physiol. 293, F121F127. doi: 10.1152/ajprenal.00478.2006

Zozulya, S., and Stryer, L. (1992). Calcium-myristoyl protein switch. Proc. Natl. Acad. Sci. U.S.A. 89, 11569-11573. doi: 10.1073/pnas.89.23. 11569
Zufall, F., and Munger, S. D. (2010). Receptor guanylyl cyclases in mammalian olfactory function. Mol. Cell. Biochem. 334, 191-197. doi: 10.1007/s11010-0090325-9

Conflict of Interest Statement: The authors declare that the research was conducted in the absence of any commercial or financial relationships that could be construed as a potential conflict of interest.

Received: 13 January 2014; accepted: 25 February 2014; published online: 17 March 2014.

Citation: Duda T, Pertzev A and Sharma RK (2014) Atrial natriuretic factor receptor guanylate cyclase, ANF-RGC, transduces two independent signals, $A N F$ and $C a^{2+}$. Front. Mol. Neurosci. 7:17. doi: 10.3389/fnmol.2014.00017

This article was submitted to the journal Frontiers in Molecular Neuroscience.

Copyright (c) 2014 Duda, Pertzev and Sharma. This is an open-access article distributed under the terms of the Creative Commons Attribution License (CC BY). The use, distribution or reproduction in other forums is permitted, provided the original author(s) or licensor are credited and that the original publication in this journal is cited, in accordance with accepted academic practice. No use, distribution or reproduction is permitted which does not comply with these terms. 